IZA DP No. 5789

The Impact of Bologna Process on the Graduate Labour Market: Demand and Supply

Giulio Bosio

Marco Leonardi

June 2011 


\title{
The Impact of Bologna Process on the Graduate Labour Market: Demand and Supply
}

\author{
Giulio Bosio \\ University of Milan \\ Marco Leonardi \\ University of Milan \\ and IZA

\section{Discussion Paper No. 5789 \\ June 2011} \\ IZA \\ P.O. Box 7240 \\ 53072 Bonn \\ Germany \\ Phone: +49-228-3894-0 \\ Fax: +49-228-3894-180 \\ E-mail: iza@iza.org
}

Any opinions expressed here are those of the author(s) and not those of IZA. Research published in this series may include views on policy, but the institute itself takes no institutional policy positions.

The Institute for the Study of Labor (IZA) in Bonn is a local and virtual international research center and a place of communication between science, politics and business. IZA is an independent nonprofit organization supported by Deutsche Post Foundation. The center is associated with the University of Bonn and offers a stimulating research environment through its international network, workshops and conferences, data service, project support, research visits and doctoral program. IZA engages in (i) original and internationally competitive research in all fields of labor economics, (ii) development of policy concepts, and (iii) dissemination of research results and concepts to the interested public.

IZA Discussion Papers often represent preliminary work and are circulated to encourage discussion. Citation of such a paper should account for its provisional character. A revised version may be available directly from the author. 
IZA Discussion Paper No. 5789

June 2011

\section{ABSTRACT}

\section{The Impact of Bologna Process on the Graduate Labour Market: Demand and Supply*}

The Bologna process inspired the Italian $3+2$ reform of the university system which constitutes a big increase in the supply of college graduates. This paper is a preliminary attempt to identify the effects of the reform on (i) the relative probability (relative to nongraduates) of employment of college graduates in the age range 25-34; (ii) their quality of employment measured with the relative probability of being employed with a temporary contract; (iii) the college wage premium. Using administrative data to identify the gradual introduction of the reform in different universities, we find that the reform increases significantly the relative employment of graduates except for women in the South where the rapid increase of female post-reform graduates has not been absorbed by the weak labour market. Finally we find that post-reform college graduates have a significantly lower college premium with respect to high school graduates than pre-reform graduates.

JEL Classification: $\quad 123,128, \mathrm{~J} 24$

Keywords: $\quad$ university reforms, college attainment, college wage premium

Corresponding author:

Marco Leonardi

Dipartimento Studi del Lavoro e del Welfare

Università Statale di Milano

Via Conservatorio 7

20122 Milano

Italy

E-mail: marco.leonardi@unimi.it

\footnotetext{
* We thank Giuseppe Bertola, Massimiliano Bratti, Lorenzo Cappellari, Daniele Checchi, Gianfranco DeSimone, Andrea Gavosto, Roberto Torrini, an anonymous referee and participants of the Fondazione Agnelli workshop on university reform 2009 and 2010 and Cide conference 2011.
} 


\section{Introduction}

Italy was among the first countries to change its university system according to European guidelines designed to make recognition of degrees easier across countries (the so called Bologna process). A system in which students could enroll into either four- or five-years degrees was abandoned in favor of a unitary two-tier system made of 3 years of general courses +2 years of specialisation degrees (henceforth called $3+2$ reform). One of the goals of the $3+2$ reform was to ensure a larger diffusion of university education among the population and in fact the $3+2$ reform not only substitutes old graduates with new $3+2$ graduates but also constitutes a big increase in the supply of college graduates. This paper is a preliminary attempt to identify the effects of the reform on (i) the relative probability of employment of college graduates in the age range 25-34; (ii) their quality of employment measured with the relative probability of being employed with a temporary contract; (iii) the college wage premium. All outcome measures are relative to non-graduates and refer to the labor market of all graduates (pre-reform and post-reform graduates alike).

We are not the first to analyze the effects of the Italian $3+2$ reform. Recent research has shown that the reform increased college education (Cappellari and Lucifora, 2009) and reduced drop-out (Di Pietro and Cutillo, 2006). Cappellari and Lucifora also show that the reform had a differential effect on individuals by family background and mostly benefitted able individuals coming from lower backgrounds. These papers look at college enrollment as dependent variable. In another study Bratti et al. (2011) consider college completion (rather than enrollment) probabilities and wage outcomes of university graduates. They focus on social gradients in educational and employment outcomes and find that the magnitude of the advantage given by parental socio-economic status is not reduced by the reform. More papers looked at other countries: Machin and Blanden (2004) analyzed the expansion of higher education in the UK and Cardoso et al. (2008) analyzed the choice of prospective students among colleges which implemented the reform in Portugal and those which did not. We join this debate studying the effect of the Italian reform on wage and employment outcomes of graduates relative to 
non graduates. We use variation in the introduction of the reform by universities to identify changes in the supply of college graduates. In this respect the paper is close to Bratti et al. (2008) who use the opening of new colleges during the 1990s in Italy to identify the change in supply and look at the effect on the probability of college enrollment (see also Currie and Moretti, 2003).

The reform was introduced in year 1999 and reached its implementation stage in the academic year 2001 through the establishment of new $3+2$ degrees. Thanks to their autonomy, each university introduced the new degrees with different timing and the first $3+2$ graduates appeared in 2002. Aggregating universities by region, we use time and region variation in the share of $3+2$ graduates to measure the variable introduction of the reform by region and to measure its effect on the graduate labor market. To instrument the share of $3+2$ graduates we exploit supply variation in the enforcement of the reform (i.e. the number of $3+2$ degrees introduced in each region and the number of students enrolled in $3+2$ degrees three years earlier) with the assumption -which we test- that universities which introduced the $3+2$ degrees more rapidly did so independently from demand conditions and the employment probabilities of their students. Since we identify the share of $3+2$ graduates with variation in supply and we show that regions with a higher share of $3+2$ graduates also have a larger total production of all (old and new) graduates in proportion to the population, we refer to the share of $3+2$ graduates as a supply shift.

The reform does two things, substitutes gradually old with new $3+2$ graduates and increases the total supply of graduates in the market. There are two potentially opposite effects of the reform on the employment probabilities of graduates (all graduates) wrt. non-graduates. On the one hand the coefficient on university reform may pick up a composition effect: the new $3+2$ graduates have different unobservable characteristics, for one they are younger and find jobs more quickly wrt. to old graduates. This effect would predict a positive effect of the reform on the relative employment rate of graduates wrt. non-graduates. On the other hand the $3+2$ reform has also increased the total supply of graduates in the market and therefore may have made their employment harder unless there is an offsetting in- 
crease in demand for graduates and/or a decline in their relative wages. Therefore if we find a negative effect of the reform on employment probabilities, this is due to an excess supply of graduates. If instead we find a positive effect, we expect to observe that the increase in supply has been accompanied with a decrease in wages. To distinguish the composition effect we should observe that the positive effect on new graduates is accompanied by an opposite effect on old graduates.

We find that the $3+2$ reform increases significantly the relative employment of male graduates. The reform affects weakly also the employment of female graduates, however, for women there are significant differences across regions. In the South the effect is reversed and the $3+2$ reform reduces the employment probabilities of female graduates relative to non-graduates which may be interpreted as an indication that the rapid increase of female graduates has not been absorbed in the labor market.

There are several reasons why an increase in the supply of graduates may have increased the employment probability of graduates relative to non-graduates (at least it did so for males). Contemporaneously to the university reform, the introduction of more flexible contracts may have increased the demand for graduates and absorbed the excess supply. Therefore in the regressions we control for demand shifts caused by two reforms of flexible contracts (see the Appendix on the "Biagi" law). Secondly the coefficient on university reform may pick up a composition effect favorable to new $3+2$ graduates. To this extent we compare old and new graduates to see if the positive effects of the reform are limited to the new graduates or spill over to all graduates. Finally we look at the effect of the reform on the probability of employment in a temporary contract and on relative wages: if the increase in the supply of graduates outstrips demand, we should observe downward pressure on the college premium and/or more graduates employed on flexible contracts (most of the times with lower wages and shorter tenure).

The results on the probability of being employed in a temporary contracts show that the university reform affects the quality of employment only for males. This result is consistent with a supply-demand framework where a large supply shift for men has been absorbed by higher flexibility of contracts - which lowered 
relative wages and thus avoided the increase of the unemployment rate - while this is not true for women in the South. Finally using National Statistics (ISTAT) data and also consistently with a picture of rising supply in the face of stable demand, we find that college graduates after the reform have a significantly lower college premium with respect to high school graduates three years after graduation, both men and women.

This paper is structured in the following way: in Section 2 we document the LFS data and present the empirical strategy. In Section 3 we document the data provided by CNVSU on the $3+2$ reform and explain the identification of the supply shifts. In Section 4 we present and discuss the results on employment probabilities and in Section 5 we describe the results on the probability of being employed on a temporary contract. In Section 6 we look at the college wage premium of postreform graduates of 2004 vs. that of pre-reform graduates of 2001 using ISTAT data. We conclude in Section 7.

\section{Data sources and model specification}

The two outcome variables of interest are the employment rate of college graduates vs. that of non-graduates and their relative probability of being employed with a temporary contract. The empirical analysis is carried out using individual data of the Italian Labour Force Survey (LFS) for the years 1998-2007. The LFS refers to the April record of each year until 2003 and then to all quarters from 2004. ${ }^{1}$ We select the sample of all individuals between 25 and 34 years of age in the years between 1998 and 2007 who are not currently full-time students.

Appendix Table 1 of the descriptive statistics shows that the distribution across regions is similar for graduates and non-graduates while the distribution across

\footnotetext{
${ }^{1}$ From the first quarter of 2004, the National Institute of Statistics (ISTAT) has introduced several changes in the LFS structure moving from a survey taken in a specific week in each quarter to a continuous survey during all weeks of the year (see De Angelini, 2006). Given the relevant discontinuity, comparisons between the old and new labour force survey are not easy; fortunately our analysis focusses on the relative employment rate (and the relative probability of being on a temporary contract) of college graduates therefore the changes should not be important as long as they affect in the same way graduates and non-graduates.
} 
sectors is more skewed towards services for graduates and to manufacturing jobs for non-graduates. The share of females is higher among graduates which constitutes slightly more than one sixth of the total sample (55,000 graduates and 320,000 nongraduates). The Table also shows the rapid increase in the number of graduates after the reform.

Figure 1 indicates that the probability of being employed is substantially higher for non-graduates than for graduates in the age range 25-34. This is not surprising because in this age range non-graduates have a much longer work experience than graduates. Unfortunately the LFS provides the information on age only in brackets and does not report the year of graduation making impossible to control for actual labor market experience. ${ }^{2}$ We put dummies for each age bracket in all regressions. The same Figure 1 shows that graduates have a significantly higher probability of being employed with a temporary contract than non-graduates. The vertical line indicates the introduction of the univeristy reform, we investigate if the relative probabilities changed with the gradual introduction of the $3+2$ reform after 2002 .

\subsection{Model specification}

To assess the impact of the reform on the relative employment rate of college graduates we could simply run the following regression on individual LFS data: $e_{i t}=\alpha+\beta_{1}$ graduate $_{i t}+\beta_{2}$ post $+\beta_{3}$ grad $_{i t} *$ post where $e_{i t}=1$ if individual $i$ is employed in year $t$ and post $=1$ if year $>=2002$. The variable graduate $_{i t}=1$ if individual $i$ holds a college degree and zero otherwise indicates the treatment group. However the introduction of the 2002 reform took place gradually in each university. As shown in the next section, using administrative data we build a "treatment intensity" variable: the share of $3+2$ graduates as percentage of the total number of graduates in each university in each year. This variable share $(3+$

\footnotetext{
${ }^{2}$ The best we can do - in the robustness section of the results- is to compare graduates aged 25-34 to non-graduates aged 16-24 and to introduce a proximate experience variable which takes value 3 and 9 for graduates in the age range 25-29 and 30-34 respectively (assuming they graduate on average at 24 before the reform and at 22 after the reform-therefore experience is 5 and 11 years for $3+2$ graduates after the reform) and 9 and 15 for non-graduates in the same age range (assuming they finish high school at 18 on average).
} 


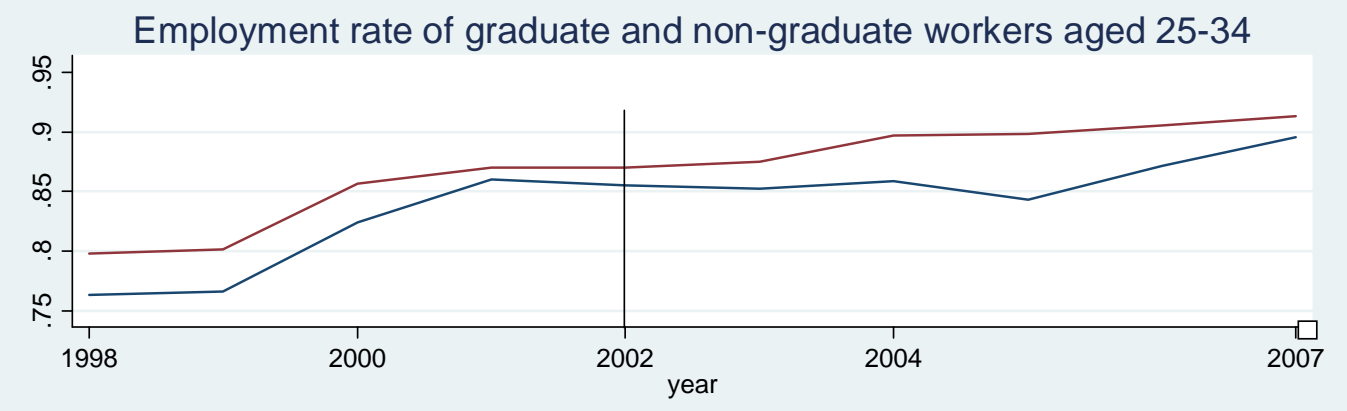

Share of graduate and non-graduate workers aged 25-34 in a temp contract

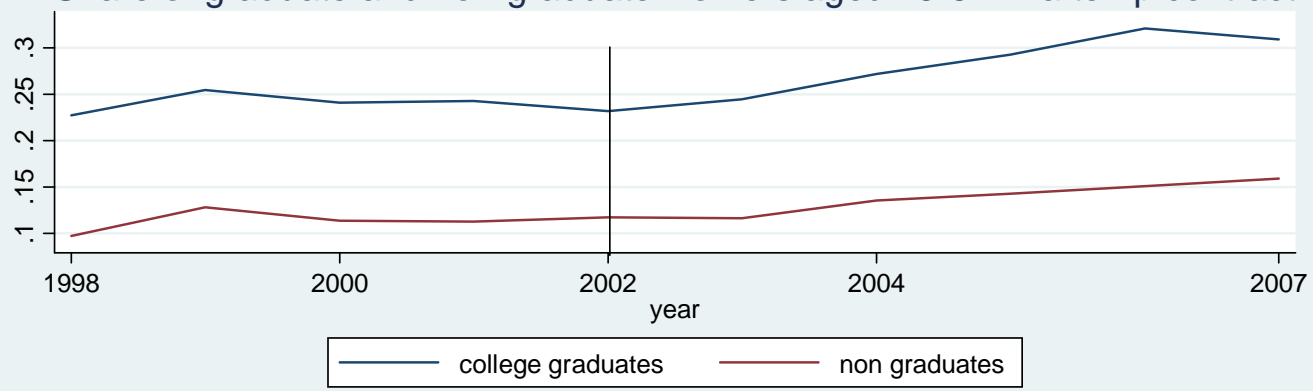

Figure 1: The employment rate and share of temporary contracts of graduates and non-graduates aged 25-34 
$2)_{j t}$ aggregated at the regional level is zero before year 2002 and measures the intensity of the reform after 2002. We match this variable to LFS data and use it instead of the simple pre-post treatment dummy.

The final specification on the LFS sample of all individuals between 25 and 34 years of age in the years between 1998 and 2007 is a linear probability model $^{3}$ :

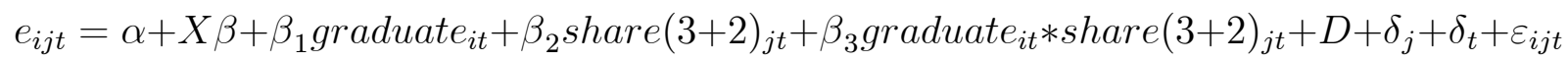

where the dependent variable $e_{i j t}$ is a dummy variable $=1$ if individual $i$ is employed in year $t$ and zero otherwise, or a dummy $=1$ if the individual is employed as a temporary worker (any type of temporary contract: apprendistato, stage, co.co.co, fixed term, etc.) and zero if he/she is employed in an open-ended contract. All estimates include a vector containing regional dummies $\delta_{j}$ that control for mean differences across regions and year dummies $\delta_{t}$ that control for time shifts common to all regions. The vector $X$ contains only a dummy for age bracket 25-29 and 30-34 and nine sector dummies. The vector $D$ contains two labor market reform dummies ref_apprit and ref_fixedt $t_{i t}$ and their interactions with the dummy graduate $_{i t}$. We introduce this term because, contemporaneous to the introduction of the $3+2$ reform, labour market reforms may have increased the relative demand for graduates and affected their relative employment probability. We model the effect of these demand shocks to avoid a potentially serious omitted variable bias. The two reforms of the apprenticeship contract and of the fixed term contract are captured by the dummies ref_appr $r_{i t}$ and ref_fixedt $t_{i t}$ which vary respectively at the regional-sectoral and at the sectoral level. The details of their construction are in the Appendix. Finally $\varepsilon_{i j t}$ is a zero-mean stochastic error term, standard errors are clustered by region and year in order to avoid that serial correlation in the

\footnotetext{
${ }^{3}$ We choose to estimate linear probability models because all covariates in equation 1 , with the exception of share $(3+2)$, are dummy variables, so the model is almost fully saturated. In the extreme case of a fully saturated model, i.e. one where all independent variables are discrete variables for mutually exhaustive categories, the linear probability model is completely general and the fitted probabilities lie within the interval $[0,1]$. Furthermore linear probability OLS models deliver unbiased and consistent estimates when variables uncorrelated with the included covariates are omitted from the regression, non-linear models such as probit or logit models do not have this property.
} 
variables may lead to biased standard errors. We run separate regressions for males and females because in some regions of Italy they have very different employment rates and in the robustness checks section we run common regressions.

The coefficient of interest is $\beta_{3}$ which picks up the effect of the university reform of graduates and tells us how the probability of employment for any graduate changes in regions where all graduates are of the old type to regions where all graduates are of the new type. The first set of results is generated by OLS estimation. To interpret this exercise as uncovering the causal effect of the university reform we need the share of $3+2$ college graduates to be uncorrelated with the residual determinants in $\varepsilon$. Essentially, we identify the effects of interest estimating a differences-in-differences model, with the source of identification being provided by the exogenous variation in the introduction of $3+2$ reform. We assume that differences between graduates and non graduates in terms of labour market outcomes are exclusively driven by the reforms, i.e. treated and control groups experience common trends. Secondly, note that in this specification we make no distinction between old and new graduates, we look at the effect of the reform on the relative employment probability of all graduates before and after the introduction of the reform i.e. we assume they face the same labor market conditions and rule out composition effects. ${ }^{4}$ Finally we assume the region as local labor market therefore graduates of one region increase supply in the same region (see next section). In the case of Italy this assumption seems quite reasonable. The inter-regional mobility of university students is low, Bratti et al. (2008) report that $84 \%$ of the graduates aged 23-31 were resident in the region in which they studied, $79 \%$ studied in the region in which they were born and regions of study, residence and birth coincide for $78 \%$ of the sample. These figures are slightly lower for Southern Italy

\footnotetext{
${ }^{4}$ Admittedly this is a strong assumption because new $3+2$ graduates may have different characteristics, but obviously the effect of the reform cannot be evaluated on them because they have no pre-treatment status. Later on we relax this assumption and look at how the variable introduction of the reform affects separately new and old graduates after 2004 (the year when the new graduates start to appear in LFS data). Assessing whether the supply of new graduates affects differentially new and old graduates requires addressing the issue of substitution and complementarity of old and new graduates. This problem is best addressed with firm-level data rather than with individual level data. DePaoli (2011) looks at substitution between new and old types in firm demand for graduates.
} 
$\left(76 \%, 80 \%\right.$ and $75 \%$, respectively) ${ }^{5}$

The second set of estimates is obtained from IV estimation. We instrument the share of $3+2$ graduates in year $t$ with the share of $3+2$ degrees and the number of enrolled students in the $3+2$ degrees three years before in year $t-3$. The assumption is that, while the share of $3+2$ graduates by region may be endogenous to the employment rate of graduates in the same region, the share of post-reform $3+2$ degrees opened in the same region three years before is likely to be more independent unless universities were targeting the graduates' employment rate when deciding on the timing of the introduction of the new degrees. For this interpretation to be legitimate, we need the share of $3+2$ degrees in $t-3$ to affect the probability of employment only through the share of $3+2$ graduates. If the supply of $3+2$ degrees simply mimics the rise in the number of individuals completing upper secondary school, i.e. if universities set up new $3+2$ degrees in regions where the demand for education is currently rising (or expected to rise), then the instruments would not be valid and the estimated effect on share $(3+$ $2)_{j t}$ could hardly be considered to be supply driven. We test the validity of the instrument in the next section. According to this identification strategy share $(3+$ $2)_{j t}$ is identified by supply changes due to universities' choices, in the next section we also show that share $(3+2)_{j t}$ is a good indicator of the total flow of graduates produced in region $j$ in year $t$ and therefore we refer to it as a supply shifter in the number of graduates in the market.

\footnotetext{
${ }^{5}$ It may be the case that some graduates moved out of the region after graduation and the coefficient of the reform could be potentially underestimated if those who left are those who could not find a job. Alternatively some individuals may have moved to regions in which the expansion of $3+2$ supply was greater because they wanted to enrol in college or because these regions had more employment opportunities (see Currie and Moretti 2003). In this case, we would be likely to overestimate the effect of university reform because of positive self-selection. Unfortunately we do not have information on individuals for whom the current region of residence coincides with the region of birth or the region where they went to school.
} 


\section{The university reform in Italy: a shift in the supply of graduates}

Although the reform was implemented in the academic year 2001/2002 across Italy, the introduction of the reform took place gradually in each university through the establishment of new $3+2$ degrees. We use the administrative data provided by the Centro Nazionale Valutazione Studi Universitari (hereafter CNVSU) for the academic years 1998/99-2007/08. The dataset provides information at the level of each single university on: (i) the number of male and female graduates in the "old" Laurea degree as well as in the first and second level $3+2$ degrees created by the reform; (ii) the number of $3+2$ degrees introduced at faculty level in each academic year; (iii) the number of male and female students enrolled in the "old" degrees and in the new $3+2$ degrees at the college level for each academic year. Appendix Table 2 shows the averages of the data by year. The first $3+2$ degrees were introduced in year 2001 and the first $3+2$ graduates appeared in $2002 .{ }^{6}$

Figure 2 shows the total number of graduates in Italy in each year $t$ divided by the population aged 25-34 (from ISTAT sources). We divide the flow of graduates in each year by the stock of the relevant population (the stock varies every year) to control for cohort size effects and demographic trends. The picture shows the total number of graduates and the old type of graduates. From 2002 the share of $3+2$ graduates (the difference between the two lines) grows and the old type of graduates gradually disappears. The reform coincides with a big increase in the supply of college graduates relative to the stock of the population aged 25-34, a doubling of the yearly supply in percentage of the population from year 2000 to 2007.

We build the percentage of $3+2$ graduates among the total graduates in each university for every academic year in the sample (1998-2008) and then we ag-

\footnotetext{
${ }^{6}$ In the first period 2002-2004, the $3+2$ graduates are those who followed old type courses and then switched to the newly introduced degrees before graduation. The "switchers" present a selection problem that we do not address here because we work with data aggregated at the level of region while the selection issue is more likely to be relevant at the level of individuals in a single university (see Bratti et al. 2011 for a treatment of this issue). The first graduates who actually followed only $3+2$ courses from the start, graduated in the the year 2004 .
} 
gregate this percentage on a regional basis (pooling all univerisities of the same region), the lowest level of aggregation which can be matched to LFS data. This variable is indicated as share $(3+2)_{j t}$ in equation 1 above and measures the "intensity" in the introduction of the reform in each region $j$ at time $t$. Aggregated at the regional level, the administrative data show a strong variation in the introduction of the $3+2$ reform. Appendix Table 3 shows that different regions have different shares of $3+2$ graduates (averaged over all years and in the first period of the introduction 2002-2004).

The variable share $(3+2)_{j t}$ not only measures the intensity of the reform but it is also a good measure of the change in the total supply of graduates in region $j$ at time $t$. Figure 3 plots share $(3+2)_{j t}$ against the total number of graduates divided by the population aged 25-34: those regions with the highest share of $3+2$ graduates are also the regions with the highest total supply of graduates in year t. Potentially share $(3+2)_{j t}$ is endogenous and rather than being supply driven it may respond to the higher demand for education in certain regions which may lead universities to produce new graduates more rapidly. The causality nexus seems to run from the share of $3+2$ graduates to the total number of graduates: if we regress the share of $3+2$ graduates on the total number of graduates divided by the population aged 25-34 using all years after 2002 the coefficient is 0.025 (0.003) e R2 è 0.35; but if we regress share of $3+2$ graduates in 2002 (the first year the new graduates appeared) on the total number of graduates divided by the population aged 25-34 in 2000 - before the introduction of the reform - the coefficient is insignificant 0.005 (0.017). This is an indication that in the first year of the reform the regions with the highest share of $3+2$ graduates were not necessarily the same as those with the highest number of graduates (relative to the population) before the reform.

\subsection{IVs and IV validity}

To isolate variation in share $(3+2)_{j t}$ due to supply changes, we use the share of $3+2$ degrees and the share of students enrolled in $3+2$ degrees as an instrument for 


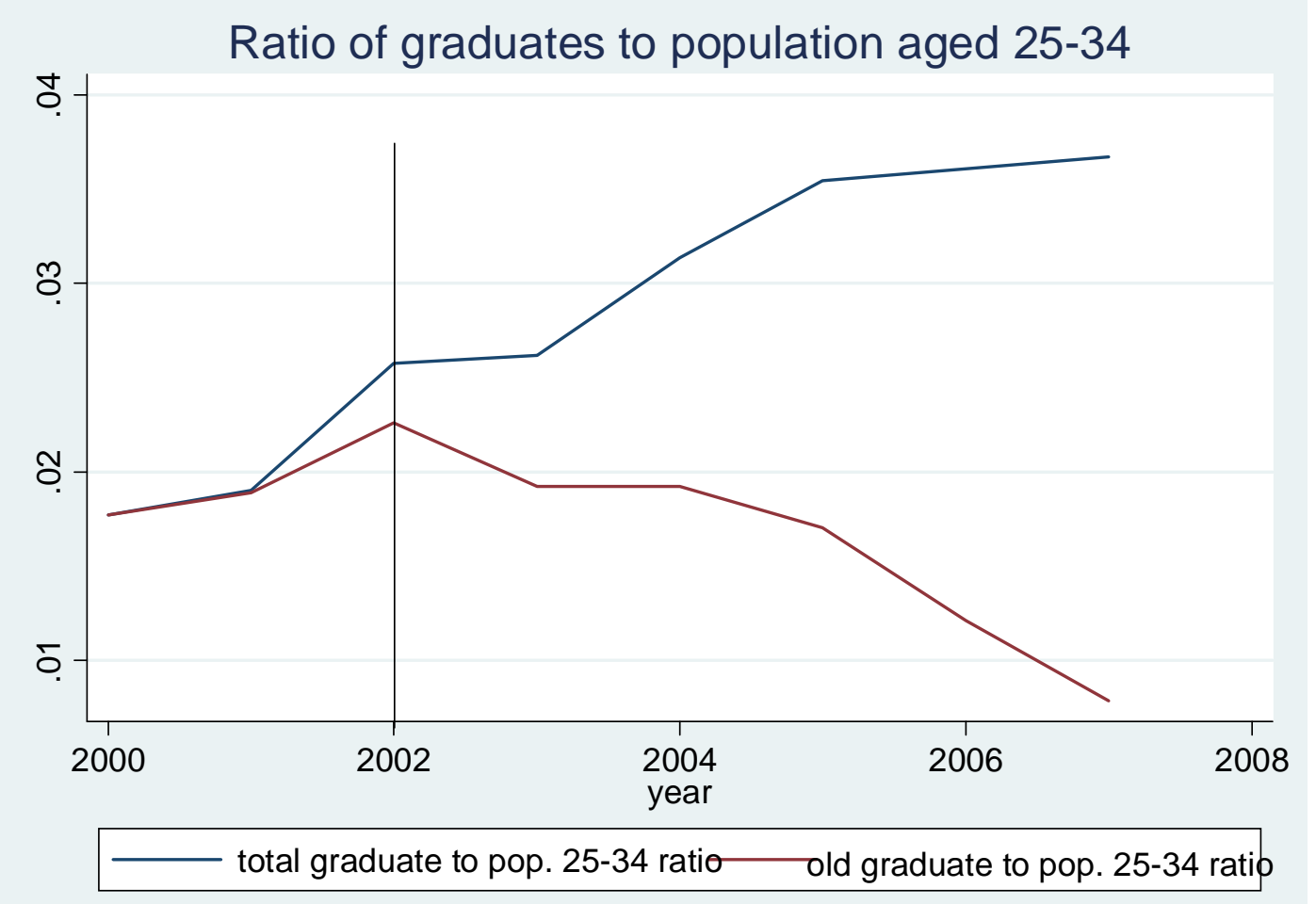

Figure 2: Ratio of total number of graduates in year $t$ on the population 2534. The vertical line indicates the appearance of the first post-reform graudates. Source: CNVSU data and population 25-34 from ISTAT LFS 2000-2007 


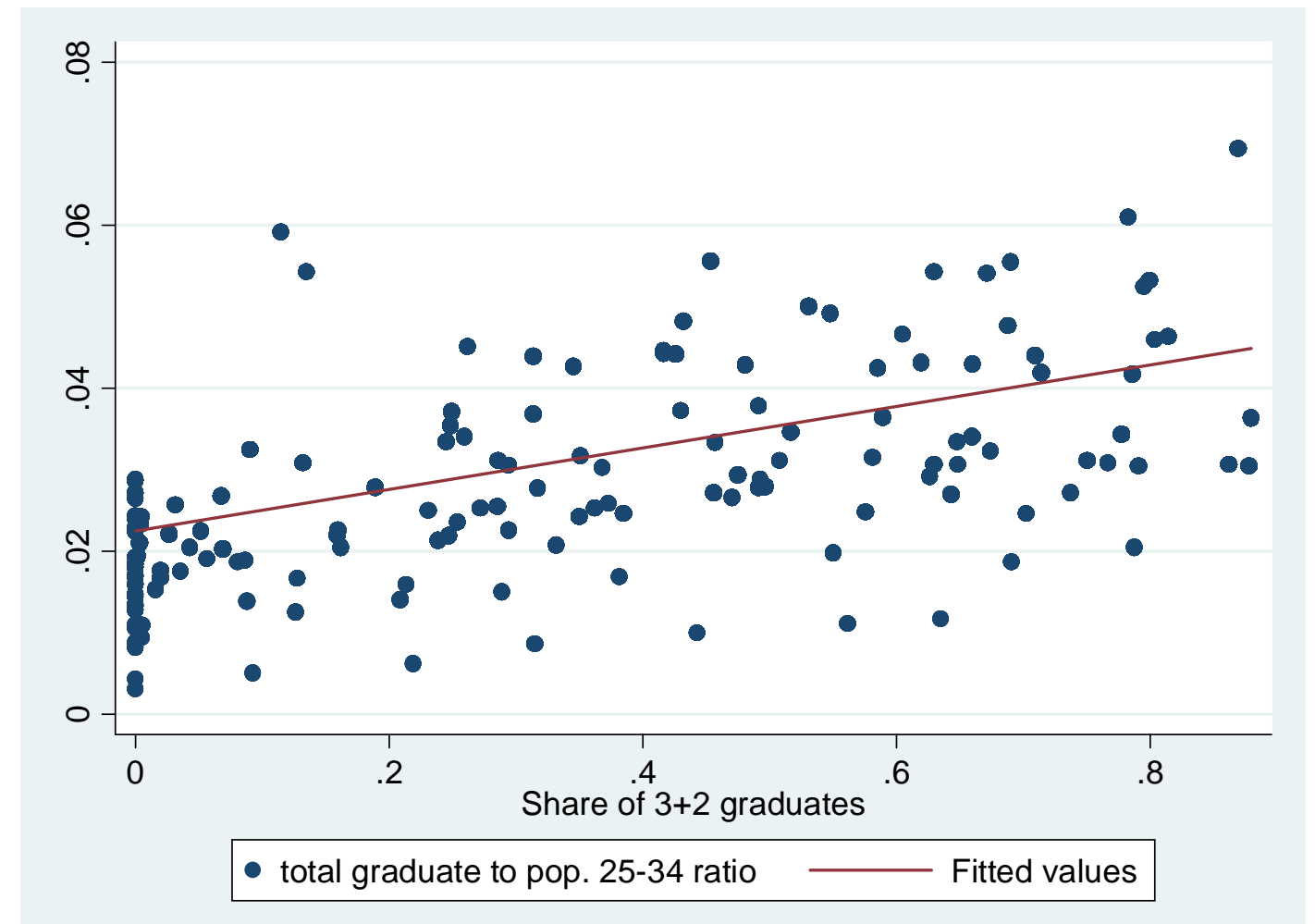

Figure 3: Scatterplot of ratio of total graduates in $t$ over the population aged 25-34 against the share of $3+2$ graduates. Each point is a region-year average. Source: CNVSU data and population 25-34 from ISTAT LFS 2000-2007. 


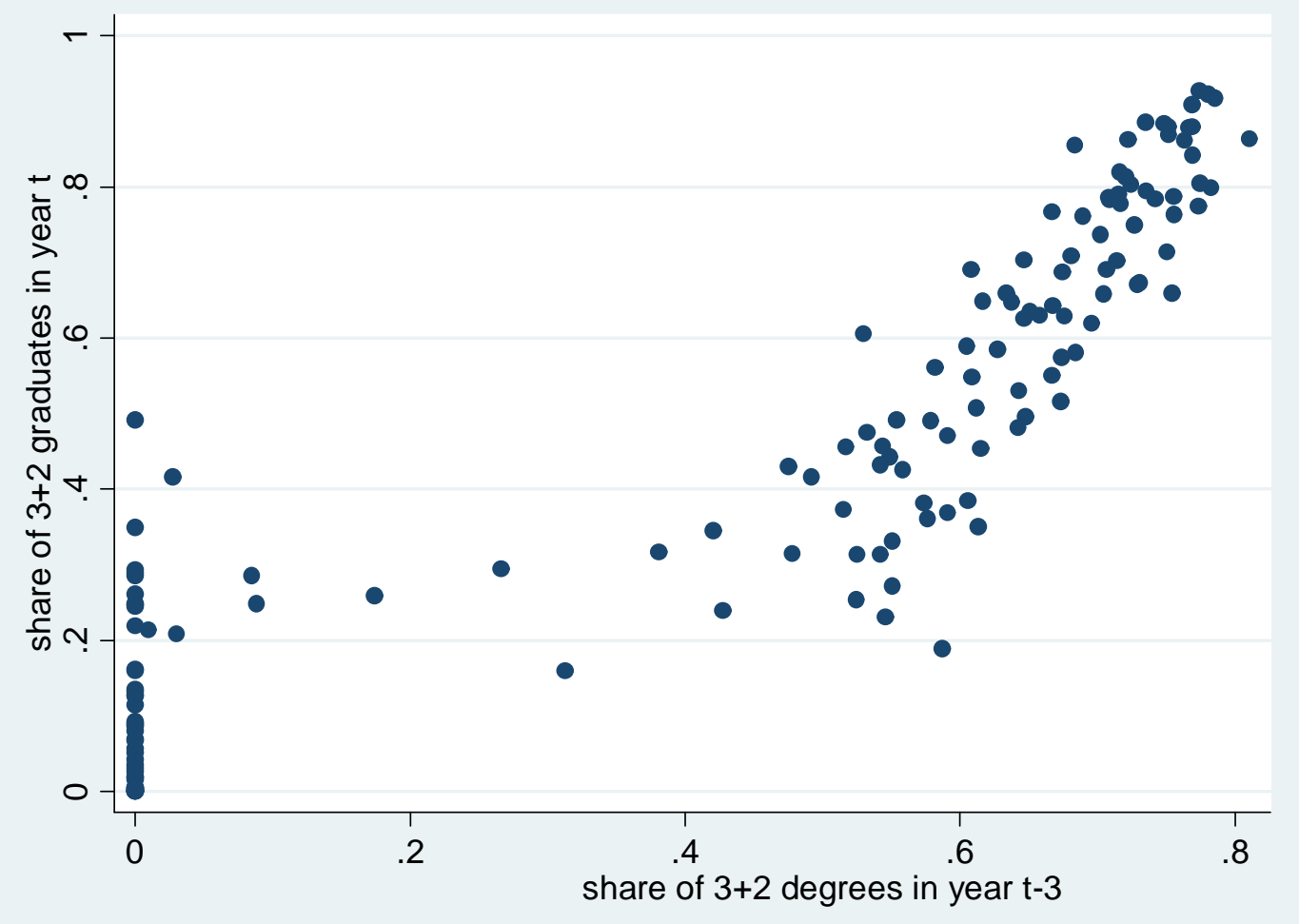

Figure 4: Scatterplot of the share of $3+2$ graduates in $t$ over the share of $3+2$ degrees opened $t$-3. Each point is a region-year average. Source: CNVSU data. 
the share of $3+2$ graduates three years later. ${ }^{7}$ Three years is the average duration of college. Using CNVSU data we construct the share of $3+2$ degrees in the total degrees for each university and the share of enrolled students in the new $3+2$ degrees, then we aggregate by region. Figure 4 plots the share of $3+2$ graduates share $(3+2)_{j t}$ against the share of the $3+2$ degrees among the total degrees offered in region $j$ in year $t-3$ : each point is a region-year average obtained pooling all universities in each region. The figure shows that the share of degrees opened three years before is a good predictor of the share of graduates in year $t$.

These instruments are valid under the assumption that universities which introduced $3+2$ degrees more rapidly did so for other reasons and irrespectively of the predicted labor market outcomes of their students. We would be worried if the universities with the best (or worst) perspectives for their graduates were also the same that introduced the reform quicker (or slower) because this would indicate that the instrument is not orthogonal to the dependent variable of interest. We can test this hypothesis matching CNVSU data to the ISTAT survey of graduates in 2001. We regress the share of $3+2$ degrees in university $j$ in between the years 2001 and 2007 (taken from CNVSU) on the average (log) wage and employment probability of the students graduated by the same university in year 2001 (taken from ISTAT survey of graduates of 2001).

Table 1 shows the result of the following regression: share $(3+2)_{j 2001-2007}=$ $a+b \log w_{j 2001}+$ remplrate $_{j 2001}+\varepsilon_{j}$ where share $(3+2)_{j 2001-2007}$ is the share of $3+2$ degrees in university $j$ between year 2001 and 2007 (columns 3 to 6 use the share of male and females enrolled in $3+2$ degrees in the same years as dependent variable). $\log w_{j 2001}$ and emplrate ${ }_{j 2001}$ are respectively the average wage and average employment rate (measured in 2004) of students graduated in university $j$ in 2001 i.e. before the reform.

The results in Table 1, unweighted and weighted by the number of students in each university, show that the speed of introduction of the reform is not related to the labor market results of the university graduates before the reform and therefore they support the validity of the instruments. The share of males and females

\footnotetext{
${ }^{7}$ We use as IV the share of students enrolled in $3+2$ degrees in addition to the share of $3+2$ degrees to account for universities which opened many $3+2$ degrees with few students each.
} 
enrolled in 3+2 degrees between years 2001 and 2007 in university $j$ (column 3 to 6 ) is always unrelated to the average labor market performance of the graduates of the same university in 2001 . The share of $3+2$ degrees is significantly related to the employment probability of the graduates of university $j$ in the unweighted regression (column 1), however it is difficult to make sense of these results since the universities with a higher share of 3+2 degrees between 2001 and 2007 are negatively related to the average wages of their students and positively related to their average employment probabilities. For this reason we conclude that these results not necessarily indicate that the universities with the higher incidence of $3+2$ degrees were acting with an eye to their students labor market perspectives and thus the instruments are valid. The opening of new degrees did not follow the potential unfilled demand, rather the increase in number of $3+2$ degrees often followed other criteria such as the availability of professors and/or of public funds across universities which resulted in an explosion of new $3+2$ degrees some of them with very low student attendance (see Bratti et al. 2008 for a similar analysis of the expansion in the number of universities in Italy during the '90s).

\section{Empirical results}

\subsection{Results for males}

Table 2 provides the results for males aged 25-34, full-time students excluded. Each column includes region and year dummies to absorb regional and time-specific effects, sectoral dummies and one dummy to control for two age brackets of age (24-29 and 30-34). The table shows both OLS linear probability models and comparable models estimated with instrumental variables (IV). Column 1 indicates that overall male graduates have a $5 \%$ lower employment rate relative to nongraduates in the age range $25-34$. This result is due to the fact that we do not control for labour market experience: a 25 years old high school graduate is much more likely to work than a college graduate of the same age.

The share of $3+2$ graduates in region $j$ at time $t$ does not significantly affect the probability of being employed for the non-graduate worker, while it positively 
affects the same chance for the college graduate worker, with a coefficient of 0.069 (0.015). ${ }^{8}$ Applying the marginal effect to a discrete variation, the quantification of this result is the following: one unit increase in the share of $3+2$ graduates means going from zero (pre-reform) to one (i.e. complete transition to the post-reform world - almost attained at the time of writing) corresponds to an increase of $7 \%$ in the relative probability of employment of college graduates wrt. high school graduates. This implies that at reform completion the $-5 \%$ points of employment rate of college graduates wrt. high school graduates of the same age 25-34 should be reversed to $+2 \%$.

The reform designed to make easier the use of the apprenticeship contract improves the employment outcomes for non-graduates with a coefficient of 0.099 (0.015) and reduces the probability of being employed for the graduates. Differently, the estimated coefficients for the reform of fixed-term contracts imply a significant and positive impact both for non-graduates and graduates. These effects are plausible because apprenticeship contracts are designed for the use of high-school graduates while fixed-term contracts are popular both among high school and college graduates.

To explore whether the estimate of the average coefficient is hiding the presence of regional differences, in column 2 we interact each variable of interest with the dummies for the three main macro-regions in Italy, respectively North, Centre and South (ISTAT definition). We find that the $3+2$ reform significantly increases the probability of employment for male graduates, with a coefficient of $0.073(0.024)$ and this effect is substantially the same across regions. The results on labor market reforms indicate more variation across regions. The reform of apprenticeship contracts significantly reduces the employment probabilities of graduates in the Centre, used as the reference group, but the effect is positive and significant for the North and the South. The reform of fixed-term contracts has increased the employment chances of both non-graduates and graduates in the Centre, but the

\footnotetext{
${ }^{8}$ Excluding fulltime students in the sample of individuals age $25-34$ we risk excluding those who are actually still studying late (probably those with the worst work prospects), i.e., we may induce an upward bias in the coefficient of the probability of being employed. We tried the same regressions including fulltime students (the number is 1980 and 1540, respectively for women and men) but there are no qualitative changes in the results.
} 
estimated coefficients indicate that the effect is significantly lower for graduates in the North.

Columns 3 and 4 replicate the same analysis using an IV approach in order to test the robustness of the previous results and to correct the possible endogeneity of the share of the $3+2$ graduates. The estimated coefficients are substantially the same. The share of the $3+2$ graduates affects positively the employment probabilities for graduates as in the previous models. The overidentification test is not always passed, but the alternative use of a single instrument produces essentially the same results.

\subsection{Results for females}

In Table 3 the same models are replicated for females. The results are weaker than those obtained for males. The estimated coefficient of the university reform for the average employment probability of college graduates across regions is $0.027(0.016)$. Unlike for males, in column 2 we detect significant differences between regions for females. In the Centre and the North of Italy the reform affects positively the employment probability of female graduates (similarly to men) but in the South the $3+2$ reform reduces significantly the employment chances for graduates $(-0.148)$. In other words, we find that the supply effect has a opposite impact in the South, reducing the relative employment probabilities of female college graduates relative to non-graduates. It seems that the increase in the number of new female graduates has not been absorbed in the South. ${ }^{9}$ Before attempting an interpretation of the results we present a series of robustness checks.

\footnotetext{
${ }^{9}$ This result is robust to the use of IV variables in column 4 (actually the negative effect in the South is much stronger with IVs). We are able to show the robustness of the result by excluding one region in turn from the regression. The coefficient estimate is stable and significantly negative, only in one case do the upper bounds of the standard errors hit marginally zero. On the contrary the results of a dynamic specification where share $(3+2)_{j t}$ has multiple leads and lags does not give significant coefficients due to overparametrization.
} 


\subsection{Robustness checks}

In Table 4 we run several robustness checks. One main issue of concern is that using the same age brackets 25-34 for both high-school and college graduates is problematic because we cannot control for the actual (and very different) labor market experience of the two groups. The interaction terms between university reform and the graduate vs. non-graduate dummy is likely to be affected by the different labour market experience and time to search for the right job match of the two groups. Ideally one would like to compare the employment outcomes of both groups within a period of time after completion of full-time studies. To this extent we constructed a sample of non graduates in the age bracket 20-24 and a treatment group of graduates in the age bracket 25-29. The results reported in column 1 show that the differences in average employment disappear (coefficient on graduate) but the differential effect of the reform on the two groups remains significant for males but not for females (panel 2). ${ }^{10}$

Another source of concern is that the results may reflect the fact that employment was already trending in a different way by region before the introduction of the reform. To this extent in column 2 and 3 we introduce region*time trends and region*time trends plus sector*time trends to account for possible pre-existing trends that may predate the adoption of the reform and could otherwise be confounded with adoption. In this case the identification is due to the discontinuity of the reform around the trend. The results appear to be robust to the inclusion of region*time trends and sector*time trends. These specifications can provide reassurance that our coefficients are not reflecting smoothly trending omitted variables (employment shifts due to regional trends and to national trends in a region industry) that are potentially correlated with the intensity of the reform. In the case of females (panel 2) controlling for trends turns out to be important because the coefficient on reform intensity turns positive and significant, probably signalling important sectoral trends in the employment of females.

\footnotetext{
${ }^{10}$ The results also hold when we use the sample of 16-24 for non graduates and 25-34 for graduates or when we impute labor market experience using a proxy. These results are available upon request.
} 
A further issue concerns the timing of the reform. The regional expansion of $3+2$ university degrees is the source of variability that we exploit to understand the relationship between the increase in the supply of college graduates and their relative probability of employment. The new degrees were first established in 2001 therefore between 2002 and 2004 the variation in the supply of $3+2$ college graduates is made by switchers who changed to the new degrees just before graduation (see note 6). Since this group is subject to selection issues that we do not address, for robustness we show in column 4 the results obtained from year 2004 inclusive onwards. The results of column 4 show that in all cases (males, females and whole sample) the effect of a higher share of $3+2$ graduates in region $j$ is stronger positive in the years after the introduction of the new system rather than when we also include the pre-reform period. This may signal the fact that since some universities allowed students who were falling backward in their studies in the old system to switch to the new $3+2$ system, this phenomenon may have created a temporary distributional effect with a shock to supply of new graduates and a likely lowering of their average quality (and employability). The results on the period 2002 onwards (not shown) are very similar.

Finally we test the robustness of the results using probit models rather than linear probability models, the marginal effects reported in column 5 are lower but still very significant for males and insignificant for females. We did not expect very different results because the linear probability model is "almost" fully saturated. (see note 6). The last panel of the table which shows the results for men and women togheter reflects the positive effect on the employment rate of males rather than the insignificant effect on females.

\subsection{Discussion of results}

In principle the positive employment effect of the reform for male graduates could simply reflect a pure compositional effect whereby the new younger and more employable graduates substitute old type of graduates. Surely new graduates are younger, may have different unobservable characteristics (the selection into college may be different) and may have accumulated a different type of knowledge at 
university. However the "composition story" is unlikely to be the full explanation of the results because the reform does not only substitute old and new graduates but also constitutes an increase in the total supply of graduates in the market. Issues of substitution and complementarity of old and new graduates are best addressed with firm-level data rather than with individual level data, however we look into the difference of the impact of the reform on new and old graduates from 2004 onwards (the first year that the information on new graduates is available in the LFS). In the "pure composition story" we should see opposite effects on the employment probabilities of old and new graduates in the regions where the share of new graduates share $(3+2)_{j t}$ is higher after 2004 . If the effect spills over to old graduates, then an effect due to the overall supply of graduates is more likely.

In Table 5 we run the same regressions as in Tables 2 and 3 distinguishing the two types of graduates. We report only the coefficients concerning the $3+2$ reform. It appears that the positive effect of the reform on the employment probability for males affects both old and new graduates although the positive effect on new graduates is stronger. For females the effect of a higher supply of new graduates is insignificant on employment probability of new graduates but it is positive on the probability of old graduates (although it is also negative for old graduates in the South, coefficient not shown). These results point to an effect that is not limited to the simple substitution of old with new graduates but rather to a supply increase that has consequences for both old and new graduates alike.

In a framework of supply and demand, if share $(3+2)_{j t}$ is a good indicator of the increase in the total supply of graduates, then we should expect an increase in the unemployment rate of graduates unless an offsetting increase in demand and/or a decline in relative wages (or an increase in temporary contracts at lower wages) has taken place. So far we have shown that, controlling for contemporaneous labor market reforms which may have increased the relative demand for graduates, male graduates have increased their relative probability of employment while women in the South have reduced theirs due to the introduction of the university reform. The difference between males and females can be explained if excess supply of female graduates in the South is not absorbed by a sufficient decline of relative 
wages. In view of explaining these results the next section investigates the effect of the university reform on the use of temporary contracts and on relative wages.

\section{Temporary employment and job quality}

In this section we look at the impact of the university reform on the job quality of both non-graduates and graduates. As a measure of job quality, we use the probability to be employed under (any type of) a temporary contract, which could be considered a good proxy for working conditions and wage levels. ${ }^{11}$

Table 6 shows that the university reform has a significant positive impact on the probability of being a temporary worker only for male graduates. We report only the IV coefficients because they are qualitatively the same as those of the OLS linear probability model. Male graduates have a $7 \%$ higher probability of being employed with temporary contracts (column 1). The increase of one unit (from pre-reform to full introduction of the reform) in the share of post-reform graduates increase by $7 \%$ the relative probability of graduates to have a temporary contract but has no effect on women. The reform of apprenticeship and of fixedterm contracts has strangely no effect on the probability of being on a temporary contract. However it may still be the case that the coefficient hides some regional differences across regional labour markets.

In column 2 we control also for the presence of regional differences. The estimated coefficients for the $3+2$ reform indicate that the university reform increases significantly the probability of temporary contracts for male graduates in the South (0.134) In columns 4 the same models are replicated for females. The $3+2$ reform has basically no effect on the probability of being a temporary workers for females

\footnotetext{
${ }^{11}$ After 2004 more detailed information on the type of temporary contract is available in the LFS, therefore it is possible to calculate the probability of employment by type of temporary contract. Between 2004-2007 temporary contracts are 16\% of total employment. Of temporary contracts: Apprendistato 6\%, CFL 5\%, Tempo determinato $71 \%$, Lavoro interinale 3\%, Altro contratto (stage, co.co.co, co.co.pro, lavoro occasionale) $15 \%$ with no substantial difference between college graduates and non-college graduates in the distribution of the types of temporary contracts. When we run our basic equation in the period 2004-2007 on the probability of being on a fixed-term contract rather than on the total temporary job we obtain similar results to Table 6 .
} 
while the reform of apprenticeship increases the probabilities of graduates to have a temporary contract in the Centre (0.057), but reduces it in the South (-0.096), see column 4 .

There are two concerns with these results. The first is that the information on age comes only in brackets and a full control for experience in the labour market is unfeasible: this could affect the estimate of the coefficient of interest "graduate $*$ share $3+2$ " because after the reform graduation is attained at a younger age and a temporary contract is likelier for younger and less-experienced workers. To this extent in robustness Table 7 we run the regressions on the sample of non-graduates age 20-24 summed to the sample of graduates aged 25-29. The results are now not significant for males and even negative for females. ${ }^{12}$ In the following column we add as additional independent variable a proxy for labour market experience which takes values 5, 9, 9 and 15 to approximate the years of labour market experience of graduates and non-graduates belonging to the age range 25-29 and 30-34 respectively. The results confirm that the $3+2$ reform had a positive effect on the probability of employment in a temporary contract although these effects are surely stronger among males rather than females.

The second concern is that the definition of temporary contract has changed in 2004 making the sample of temporary workers potentially discontinuous across time. ${ }^{13}$ To investigate these issues further we run the regressions on a sample restricted to years 2004-2007 for homogenous measurement of the temporary contracts (column 4). Again the results are not significant.

In conclusion the university reform has increased the relative probability of employment in temporary contracts for males and had no effect for females. Although the results for males are not robust to controls for labor market experience and

\footnotetext{
${ }^{12}$ Furthermore - and similarly to the case of employment probabilities - controlling for experience makes the base difference (the coefficient graduate) in temporary employment probabilities between graduates and non graduates disappear at least for males.

${ }^{13}$ In the old LFS the identification of a temporary job depends on the respondent's perception which leads to underestimating the total number of people formally employed under fixed-term contracts (Tattara and Valentini, 2010; Barbieri and Sestito, 2008). In the new labour force survey (RCFL), the self-perception criteria has been replaced with questions designed to better reconstruct the real contract type of those individuals who declare themselves to be employed, and to recover the short-term jobs often hidden in the previous system.
} 
to diferent time spans, they hold when adding region*year ad sector*year trends (column 3) and to probit models (column 5).

\section{College wage premium}

So far we have examined how the positive effect of the reform on the number of graduates has led to a deterioration of employment conditions, in terms of a higher share of graduates employed in temporary contracts relative to non-graduates. Another potential adjustment mechanism is through relative wages: when the relative supply of graduates increases, market equilibrium is restored through a reduction in their relative wages. In this section we provide preliminary evidence on this hypothesis. ${ }^{14}$

Since the LFS does not collect information on wages until 2009, we look at the college wage premium by pooling the data from four ISTAT surveys: the 'Survey on the college-to-work transitions of university graduates of 2001 and of 2004' and the 'Survey on the school-to-work transitions of high school graduates of 2001 and of 2004'. The four surveys collect information on the post-graduation wages of high school and of college graduates of a given year, collected three years after graduation. Pooling data from the survey of high school graduates and of college graduates, it is possible to estimate the college wage premium of graduates of 2001 (pre-reform) and of 2004 (post-reform).

We pool all four surveys in a single dataset of high school and college graduates in the year 2001 and 2004 whose wages are collected in the years 2004 and 2007. The descriptive statistics are in Appendix Table 4 divided by year and in total. We run the following regression:

\footnotetext{
${ }^{14}$ The analysis of the wage effects of the reform deserves further research aimed at tackling the issue of selection of students from old courses in the post-reform $3+2$ courses and, within the new system, the selection from the first three years of college into the two specialisation years. These issues are the focus of a companion paper (Bratti, Cappellari and Leonardi, 2011). In this present paper we report only a descriptive analysis aimed at testing the validity of the simple supply and demand framework as a framework for thought.
} 
$\log w_{i t}=\alpha+X \beta+\gamma_{1}$ graduate $_{i}+\gamma_{2}$ year $07+\gamma_{3}\left(\right.$ year $07 *$ graduate $\left._{i}\right)+e_{i t}$

where $t$ is equal either to 2004 or 2007 (henceforth we use the year of interview rather than the year of graduation to denote time). The log net monthly wages (nominal wages, not deflated) three years from graduation is regressed on $X$ which includes a set of individual characteristics (female dummy, the age is in brackets), job characteristics (temporary contract, part-time, sector of activity) and subject and final mark of graduation; on a dummy graduate which indicates the college premium in 2004 and on the interaction year $07 *$ graduate which indicates the college premium of 2007 relative to 2004.

This exercise is purely descriptive, the main identifying assumption is that, conditional on the covariates, graduates in year 2001 and in year 2004 are "the same". In order to increase the credibility of this assumption, we estimated specifications including college major fixed effects and university fixed effects. When both college major and university fixed effects are included in the analysis, we will be investigating the differences in the college wage premium of graduates of 2001 and of 2004 in the same college major and from the same university. Controlling for both college major and university fixed effects is important as educational standards and labor market outcomes are likely to systematically differ both among college majors (Ballarino and Bratti 2009, Buonanno and Pozzoli 2009) and among universities (Brunello and Cappellari 2008, Bagüès et al 2009, Di Pietro and Cutillo 2006). Furthermore the reform - which affects the college premium of graduates in 2004 measured in 2007 - is likely to have changed the college major mix among graduates and the distribution of graduates across universities may also have changed, in case some institutions expanded their offer especially of short degrees. Finally, as any change in the business cycle which may affect wages of treated and controls differently in the two periods will be captured by the reform dummy, we inserted in the regression the regional unemployment rate of the age group 25-34.

Table 8 (column 1) for males indicates that college graduates have in 2004 a premium of $29 \%$ but this is reduced by $7 \%$ in 2007 . There are very little differences 
across specifications and even when controlling for university fixed effects in 2007 the loss is of $7 \%$ i.e., graduate students of the same university in 2007 have a college premium reduced by $7 \%$ in 2007 wrt. 2004. The results for females are qualitatively similar (Table 9). Female graduates in 2004 enjoy a larger premium than men at around $42 \%$, in 2007 the premium falls off around $8 \%$ even controlling for graduation in the same universities. The interactions with North and South in columns 3 indicate that the excess supply of female college graduates in the South of Table 3 is not reflected on the female college premium in the South in 2007 (coefficient Graduate $*$ year $07 *$ South of Table 9 is insignificant).

The reduction of the wage premium is due to a composition effect or is it the effect of an increase in supply? Again we do not have a bullet-proof reply because the reform both substitutes new to old graduates and increases the number of college graduates. However we look for hints. In 2004, the first cohort of postreform students enrolled under the reformed system completed their studies, while, in parallel, students from the old system were still graduating from universities i.e. the college wage premium of graduates of year 2004 (measured in 2007) is a mix of pre-reform and post-reform wage premia. In the last column of Tables 8 and 9 we compare the college premium of old graduates in 2004 and 2007. New graduates males and females alike - earn on average $4 \%$ less than old graduates (in 2007, the only year when we can measure new graduates) but the reduction of the college premium between 2004 and 2007 is not due only to the presence of new graduates because it is reduced for old graduates too. The wage premium of an old graduate in 2004 was $35 \%$ for males and is reduced by $5 \%$ in 2007 ; it was of $56 \%$ for females and is reduced by $6 \%$ in 2007 . This is further indication that the reform is not only a composition effect but the supply effect has reduced wages of old graduates too.

\section{Conclusions}

The university reform introduced in Italy in 2002 prompted an increase in the supply of graduates. We use administrative data on the number of new degrees 
opened by universities to build a measure of the change in supply by region and year and measure the effects of the $3+2$ reform on the labour market for graduates.

For males the positive effect of the reform on employment probabilities of graduates is uniform across regions while for females the effect is weakly positive on average but negative in the South possibly indicating an excess supply of college graduates. We advance some possible interpretations of the positive effect of the supply expansion on male graduates. These results are obtained controlling for contemporaneous introduction of labor market reform therefore the difference is unlikely to be due to omitted labor demand variables. Surely there is a mechanical composition effect when new $3+2$ graduates - who are younger and more employable - substitute old type graduates. However the results after 2004 indicate that the effect of the $3+2$ reform extends to old graduates. We favor an explanation based on a supply-demand framework: supply shifts due to the $3+2$ reform increases the relative employment rate of graduates because the contemporaneous advent of labour market reforms increased the employment rate of graduates in (low-wage) temporary contracts thus avoiding an increase in unemploment. Excess supply creates downward pressure on the graduate premium. This is confirmed by the analysis of the ISTAT data which show a reduction of the college premium after the reform: the wage premium measured in 2007 is reduced by $7 \%$ for males wrt. to 2004. These results hold even for students graduating from the same universities in the same majors and are consistent with the evidence on declining entry wages of new graduates by Rosolia and Torrini (2007) and Naticchioni and Ricci (2009). Again the composition effect does not seem to be the full explanation because lower graduate wages after the reform are certainly due to the negative penalty that new $3+2$ graduates suffer wrt. old graduates after the reform, but also old-type of graduates earn around $5 \%$ less than before the reform.

Two results may help explain the contrast between the positive effect of the supply expansion on male graduates and a negative effect on females in the South. First, only for males do we find a significant effect on the quality of employment (measured as the probability of employment in a temp contract). Second, the negative effect of the reform on employment probabilites is not reflected in a decline 
of female graduate wages in the South where the excess supply of female college graduates is more evident. In conclusion for females in the South the increase in the supply of graduates is not absorbed by a higher employment rate in temporary contracts nor by a particular decline of wages in the South therefore their relative employment rate is reduced.

Further analysis and better data are certainly needed to refine the analysis and overcome the limitations of this paper especially regarding the lack of information on the actual labor market experience and on the university of graduation of individuals. To distinguish the composition hypothesis from the theory that assumes a spill over of the supply of new graduates on the outcomes of all graduates, it is necessary to look at substitution effects in the demand of firms and to look deeper in the wage and employment effects of the reform taking into account the selection

process into the second tier of the university reform (see Bratti, Cappellari and Leonardi 2011).

\section{References}

[1] Bagüès, M., Sylos-Labini, M. and Zinovyeva, N. (2008), "Differential grading standards and university funding: Evidence from Italy", CESifo Economic Studies, 54(2): 149-176.

[2] Ballarino, G. and Bratti, M. (2009), "Field of Study and University Graduates' Early Employment Outcomes in Italy during 1995-2004", Labour, 23(3): $421-457$.

[3] Barbieri G. and P. Sestito (2008), "Temporary workers in Italy: who are they and where they end up", Labour, vol. (22), pp. 127-166.

[4] Bratti M., Broccolini C. and S. Staffolani (2007), "Higher education reform, student time allocation and academic performance in Italy: Evidence from a faculty of Economics", Rivista Italiana degli Economisti, vol 15(2): 275-304 
[5] Bratti M., Cappellari L. and M. Leonardi (2011), "Higher Education Reform and University Graduates' Labor Market Outcomes", mimeo

[6] Bratti M., Checchi D.and G. de Blasio (2008). "Does the Expansion of Higher Education Increase the Equality of Educational Opportunities? Evidence from Italy," Labour, vol. 22(s1), pp. 53-88,

[7] Brunello G. and L. Cappellari (2008), "The labour market effect of Alma Mater: Evidence from Italy", Economics of Education Review, vol. 27(5), pp. $564-574$

[8] Buonanno, P. and Pozzoli, D. (2009), "Early Labour Market Returns to College Subject", Labour, 23(4), 559-588.

[9] Cappellari L., Dell'Aringa C. and M. Leonardi (2009), "Flexible employment, job flows and labour productivity", forthcoming IZA dp series

[10] Cappellari, L. and C. Lucifora (2009) "The Bologna process and college enrolment decisions", Labour Economics, 16(6): 638-647.

[11] Cardoso A.R., Portela, M., Sá C. and F. Alexandre (2008) "Demand for Higher Education Programs: The Impact of the Bologna Process", CESIfo Economic Studies, 54(2): 229-247.

[12] Currie, J. and Moretti, E. (2003), "Mother's education and the intergenerational transmission of human capital: evidence from college openings", Quarterly Journal of Economics, 118: 1495-1532.

[13] De Angelini A. (2006), "Dalla RTFL alla RCFL: Cosa cambia nella rappresentazione del mercato del lavoro veneto?", I Tartufi, n. 23; maggio

[14] De Paoli A. (2011), "The demand for skilled workers after the '3+2' university reform", mimeo

[15] Di Pietro, G. and A. Cutillo (2006) "University quality and labour market outcomes in Italy", Labour, 20(1): 37-62. 
[16] Machin S. and J. Blanden (2004) "Educational Inequality and the Expansion of UK Higher Education", Scottish Journal of Political Economy, 51(2): 230249.

[17] Naticchioni P. and A. Ricci (2009), "Decreasing wage inequality in Italy: the role of demand and supply for education", working paper DE-ISFOL, n.9.

[18] Rosolia A. and R. Torrini (2007), "The generation gap: relative earnings of young and old workers in Italy", Economic working papers, n. 639, Bank of Italy.

[19] Tattara G. and M. Valentini (2010), "Turnover and Excess Worker Reallocation. The Veneto Labour Market between 1982 and 1996", Labour, vol. 24(4), pp. $474-500$.

\section{APPENDIX: LABOR MARKET REFORM DUMMIES}

Contemporaneous to the introduction of the $3+2$ reform, labour market reforms may have increased the relative demand for graduates. As in other European countries, a series of measures introduced various kinds of fixed-term and temporary contracts without changing the legislation on permanent, open-ended, contracts. Our analysis focusses on the reform of the fixed-term contract of 2001 and the new apprenticeship contract of the Biagi Law in 2003. For semplicity, and because they are both part of the overall labour market reform written by the same person, Marco Biagi, we call both of them "Biagi law". Both reforms aimed at making the use of fixed-term and apprenticeship caontracts easier for firms. For the institutional details of the reforms see Cappellari et al. (2009). We use regional and regional-sector variation in these two reforms to identify the potential demand shifts to graduates' employment rate. The fixed term contract eform of 2001 was implemented through collective bargaining agreements only from 2005 onwards. We build a dummy (indicated as ref_fixedt $t_{i t}$ in Equation 1) to indicate the reform of fixed-term contracts, which takes the value one from 2005 on, in the following sectors: textiles, wood, chemicals, commerce, construction, foodstuffs. The implementation of the apprenticeship contract reform of 2003 required a set 
of regulations to be issued by the regions. In 2006 the government acted to substitute the regions which had been slow with the regulations in some sector through collective agreements. We build one dummy (indicated as ref_appr ${ }_{i t}$ in Equation 1) which indicates the reform of the apprendistato and takes the value one after 2005 in two regions, Emilia Romagna and Tuscany, which enacted regional laws to enable the use of the new contract by all firms. And in another four regions (in different quarters) after 2006: Friuli, Marche, Sardinia and the autonomous province of Bolzano. The dummy takes the value one in 2006 and after in the following sectors: foodstuffs, chemicals, energy, commerce, banking, construction, wood, textiles, transport and mechanical engineering. The variable 'ref_appr ${ }_{i t}$ ' varies at the region and sector level. 
Table 1: Validity test of IVs: the relationship betw. the gradual introduction of $3+2$ and labor market performance of graduates before the reform

\begin{tabular}{lcccccc}
\hline & \multicolumn{2}{c}{$\begin{array}{c}\text { share 3+2 degrees } \\
\text { in 2001-2007 }\end{array}$} & \multicolumn{2}{c}{$\begin{array}{c}\text { share males in 3+2 } \\
\text { in 2001-2007 }\end{array}$} & \multicolumn{2}{c}{$\begin{array}{c}\text { share females in 3+2 } 2001-2007 \\
\text { in }\end{array}$} \\
\cline { 2 - 6 } log average wage 2001 & unweighted & weighted & unweighted & weighted & unweighted & weighted \\
\cline { 2 - 6 } & 0.104 & 0.213 & 0.107 & 0.241 & 0.206 & 0.356 \\
average empl. rate 2001 & $(0.113)$ & $(0.209)$ & $(0.136)$ & $(0.228)$ & $(0.152)$ & $(0.223)$ \\
& -0.231 & -0.151 & -0.015 & 0.015 & -0.048 & -0.010 \\
constant & $(0.084)^{* * *}$ & $(0.155)$ & $(0.106)$ & $(0.169)$ & $(0.098)$ & $(0.166)$ \\
& -0.089 & -0.909 & -0.262 & -1.232 & -0.952 & -2.039 \\
R-squared & $(0.765)$ & $(1.410)$ & $(0.911)$ & $(1.541)$ & $(1.032)$ & $(1.505)$ \\
$\mathrm{N}$ & 0.004 & 0.002 & 0.001 & 0.003 & 0.003 & 0.005 \\
& 616 & 616 & 616 & 616 & 616 & 616
\end{tabular}

Notes: OLS regressions on data at the level of university on the introduction of the $3+2$ reform on average labour market performance of graduates before the reform. The average wage and average employment rate of students graduated in 2001 are taken from ISTAT 2001 survey. Weights are the number of students by university in each year. 
Table 2: The effect of $3+2$ reform on employment probabilities: males

\begin{tabular}{|c|c|c|c|c|}
\hline & $(1)$ & $(2)$ & (3) & $(4)$ \\
\hline & OLS & OLS interactions & IV & IV interactions \\
\hline \multirow[t]{2}{*}{ Graduate (dummy) } & -0.056 & -0.066 & -0.050 & -0.061 \\
\hline & $(0.006)^{* * *}$ & $(0.010)^{* * *}$ & $(0.006)^{* * *}$ & $(0.010)^{* * *}$ \\
\hline \multirow[t]{2}{*}{ Share $3+2$} & -0.083 & 0.011 & -0.032 & 0.014 \\
\hline & $(0.054)$ & $(0.052)$ & $(0.066)$ & $(0.067)$ \\
\hline \multirow{2}{*}{ Graduate*share $3+2$} & 0.069 & 0.073 & 0.051 & 0.058 \\
\hline & $(0.015)^{* * *}$ & $(0.024)^{* * *}$ & $(0.015)^{* * *}$ & $(0.032)^{*}$ \\
\hline \multirow[t]{2}{*}{ Reform appr } & 0.099 & 0.077 & 0.097 & 0.076 \\
\hline & $(0.015)^{* * *}$ & $(0.019)^{* * *}$ & $(0.015)^{* * *}$ & $(0.021)^{* * *}$ \\
\hline \multirow[t]{2}{*}{ Graduate*ref_appr } & -0.020 & -0.032 & -0.014 & -0.027 \\
\hline & $(0.009)^{* *}$ & $(0.013)^{* *}$ & $(0.009)$ & $(0.016)^{*}$ \\
\hline \multirow[t]{2}{*}{ Reform_fixedterm } & 0.081 & 0.061 & 0.080 & 0.060 \\
\hline & $(0.009)^{* * *}$ & $(0.007)^{* * *}$ & $(0.009)^{* * *}$ & $(0.008)^{* * *}$ \\
\hline \multirow[t]{2}{*}{ Graduate*ref_fterm } & 0.013 & 0.039 & 0.016 & 0.041 \\
\hline & $(0.005)^{* *}$ & $(0.009)^{* * *}$ & $(0.005)^{* * *}$ & $(0.009)^{* * *}$ \\
\hline \multirow[t]{2}{*}{ Graduate*share $3+2 *$ North } & & 0.005 & & 0.042 \\
\hline & & $(0.027)$ & & $(0.035)$ \\
\hline \multirow[t]{2}{*}{ Graduate*share $3+2 *$ South } & & -0.042 & & -0.095 \\
\hline & & $(0.042)$ & & $(0.055)^{*}$ \\
\hline \multirow[t]{2}{*}{ Graduate*ref_appr*North } & & 0.025 & & 0.010 \\
\hline & & $(0.015)^{*}$ & & $(0.018)$ \\
\hline \multirow[t]{2}{*}{ Graduate*ref_appr*South } & & 0.056 & & 0.072 \\
\hline & & $(0.021)^{* * *}$ & & $(0.027)^{* * *}$ \\
\hline \multirow[t]{2}{*}{ Graduate*ref_fterm*North } & & -0.028 & & -0.033 \\
\hline & & $(0.010)^{* * *}$ & & $(0.010)^{* * *}$ \\
\hline \multirow[t]{2}{*}{ Graduate*ref_fterm*South } & & -0.017 & & -0.010 \\
\hline & & $(0.015)$ & & $(0.016)$ \\
\hline \multirow[t]{2}{*}{ Share $3+2$ Test $\mathrm{F}$} & & & 36.45 & 44.80 \\
\hline & & & $(0.000)$ & $(0.000)$ \\
\hline \multirow[t]{2}{*}{ Graduate*Share $3+2$ Test $\mathrm{F}$} & & & 281.76 & 211.25 \\
\hline & & & $(0.000)$ & $(0.000)$ \\
\hline \multirow[t]{2}{*}{ Test of overidentifying } & & & 6.669 & 13.422 \\
\hline & & & $(0.154)$ & $(0.098)$ \\
\hline Observations & 215212 & 215212 & 215212 & 215212 \\
\hline R-squared & 0.09 & 0.10 & & \\
\hline
\end{tabular}

Notes: Dependent variable is a dummy indicating whether the individual is employed or not. All specifications control for region, age 30-34, sector and year dummies. In column 2 and 4 only the triple interaction terms interacted with "graduate dummy" are shown. Estimation is by linear probability model and IV. Clustered standard errors are reported in parentheses. $*$ significant at $10 \%$; * significant at $5 \%$; ** significant at $1 \%$. 
Table 3: The effect of $3+2$ reform on employment probabilities: females

\begin{tabular}{|c|c|c|c|c|}
\hline & (1) & $(2)$ & $(3)$ & $(4)$ \\
\hline \multirow{3}{*}{ Graduate (dummy) } & OLS & OLS interactions & IV & IV interactions \\
\hline & -0.006 & -0.036 & 0.001 & -0.029 \\
\hline & $(0.008)$ & $(0.011)^{* * *}$ & $(0.008)$ & $(0.012)^{* *}$ \\
\hline \multirow[t]{2}{*}{ Share $3+2$} & -0.108 & 0.008 & -0.069 & -0.004 \\
\hline & $(0.077)$ & $(0.059)$ & $(0.092)$ & $(0.079)$ \\
\hline \multirow[t]{2}{*}{ Graduate*Share $3+2$} & 0.027 & 0.067 & 0.008 & 0.042 \\
\hline & $(0.016)^{*}$ & $(0.033)^{* *}$ & $(0.018)$ & $(0.039)$ \\
\hline \multirow[t]{2}{*}{ Reform_appr } & 0.101 & 0.090 & 0.099 & 0.083 \\
\hline & $(0.014)^{* * *}$ & $(0.019)^{* * *}$ & $(0.014)^{* * *}$ & $(0.022)^{* * *}$ \\
\hline \multirow[t]{2}{*}{ Graduate*ref_appr } & -0.037 & -0.034 & -0.030 & -0.025 \\
\hline & $(0.009)^{* * *}$ & $(0.019)^{*}$ & $(0.010)^{* * *}$ & $(0.021)$ \\
\hline \multirow[t]{2}{*}{ Reform_fixedterm } & 0.093 & 0.094 & 0.092 & 0.092 \\
\hline & $(0.010)^{* * *}$ & $(0.008)^{* * *}$ & $(0.010)^{* * *}$ & $(0.007)^{* * *}$ \\
\hline \multirow[t]{2}{*}{ Graduate*ref_fterm } & 0.009 & 0.026 & 0.012 & 0.028 \\
\hline & $(0.007)$ & $(0.011)^{* *}$ & $(0.007)^{*}$ & $(0.011)^{* *}$ \\
\hline \multirow[t]{2}{*}{ Graduate*Share $3+2 *$ North } & & -0.004 & & 0.038 \\
\hline & & $(0.036)$ & & $(0.044)$ \\
\hline \multirow[t]{2}{*}{ Graduate*Share $3+2 *$ South } & & -0.148 & & -0.205 \\
\hline & & $(0.056)^{* * *}$ & & $(0.069)^{* * *}$ \\
\hline \multirow[t]{2}{*}{ Graduate*Ref_appr*North } & & 0.006 & & -0.012 \\
\hline & & $(0.020)$ & & $(0.023)$ \\
\hline \multirow[t]{2}{*}{ Graduate*Ref_appr*South } & & 0.011 & & 0.029 \\
\hline & & $(0.030)$ & & $(0.036)$ \\
\hline \multirow[t]{2}{*}{ Graduate*Ref_fterm*North } & & -0.028 & & -0.034 \\
\hline & & $(0.012)^{* *}$ & & $(0.012)^{* * *}$ \\
\hline \multirow[t]{2}{*}{ Graduate*Ref_fterm*South } & & 0.005 & & 0.011 \\
\hline & & $(0.020)$ & & $(0.020)$ \\
\hline \multirow[t]{2}{*}{ Share $3+2$ Test $\mathrm{F}$} & & & 23.92 & 42.53 \\
\hline & & & $(0.000)$ & $(0.000)$ \\
\hline \multirow[t]{2}{*}{ Graduate* Share $3+2$ Test $\mathrm{F}$} & & & 271.72 & 223.81 \\
\hline & & & $(0.000)$ & $(0.000)$ \\
\hline \multirow[t]{2}{*}{ Test of over-identifying } & & & 2.434 & 7.650 \\
\hline & & & $(0.656)$ & $(0.468)$ \\
\hline Observations & 165977 & 165977 & 165977 & 165977 \\
\hline $\mathrm{R}$-squared & 0.12 & 0.13 & & \\
\hline
\end{tabular}


Table 4: Robusteness check on employment probabilities

\begin{tabular}{|c|c|c|c|c|c|}
\hline & $(1)$ & $(2)$ & (3) & (4) & $(5)$ \\
\hline & OLS & OLS & OLS & OLS & Probit \\
\hline & \multicolumn{5}{|c|}{ MALES } \\
\hline & 2024 vs. 2529 & trendreg & trendreg\&sec & post2004 & probit \\
\hline \multirow[t]{2}{*}{ Graduate } & -0.015 & -0.056 & -0.146 & -0.189 & -0.041 \\
\hline & $(0.013)$ & $(0.006)^{* * *}$ & $(0.006)^{* * *}$ & $(0.013)^{* * *}$ & $(0.005)^{* * *}$ \\
\hline \multirow[t]{2}{*}{ Share $3+2$} & -0.177 & -0.139 & -0.106 & 0.035 & -0.012 \\
\hline & $(0.107)$ & $(0.049)^{* * *}$ & $(0.043)^{* *}$ & $(0.046)$ & $(0.031)$ \\
\hline \multirow[t]{2}{*}{ Graduate*Share $3+2$} & 0.096 & 0.069 & 0.055 & 0.135 & 0.028 \\
\hline & $(0.031)^{* * *}$ & $(0.014)^{* * *}$ & $(0.011)^{* * *}$ & $(0.021)^{* * *}$ & $(0.009)^{* * *}$ \\
\hline Observations & 72923 & 215212 & 215212 & 141197 & 215212 \\
\hline \multirow[t]{3}{*}{ R-squared } & 0.14 & 0.09 & 0.36 & 0.35 & \\
\hline & \multicolumn{5}{|c|}{ FEMALES } \\
\hline & 2024 vs. 2529 & trendreg & trendreg\&sec & post 2004 & probit \\
\hline \multirow[t]{2}{*}{ Graduate } & 0.039 & -0.006 & -0.101 & -0.142 & -0.004 \\
\hline & $(0.012)^{* * *}$ & $(0.008)$ & $(0.005)^{* * *}$ & $(0.013)^{* * *}$ & $(0.005)$ \\
\hline \multirow[t]{2}{*}{ Share $3+2$} & -0.182 & -0.187 & -0.116 & 0.094 & -0.010 \\
\hline & $(0.113)$ & $(0.074)^{* *}$ & $(0.058)^{* *}$ & $(0.076)$ & $(0.048)$ \\
\hline \multirow[t]{2}{*}{ Graduate*Share $3+2$} & 0.031 & 0.027 & 0.049 & 0.122 & 0.019 \\
\hline & $(0.029)$ & $(0.016)^{*}$ & $(0.013)^{* * *}$ & $(0.022)^{* * *}$ & $(0.013)$ \\
\hline Observations & 60896 & 165977 & 165977 & 109266 & 165977 \\
\hline \multirow[t]{3}{*}{ R-squared } & 0.17 & 0.12 & 0.52 & 0.51 & \\
\hline & \multicolumn{5}{|c|}{ ALL SAMPLE } \\
\hline & 2024 vs 2529 & trendreg & trendreg\&sec & post 2004 & probit \\
\hline \multirow[t]{2}{*}{ Graduate } & 0.008 & -0.037 & -0.127 & -0.171 & -0.023 \\
\hline & $(0.011)$ & $(0.006)^{* * *}$ & $(0.005)^{* * *}$ & $(0.011)^{* * *}$ & $(0.004)^{* * *}$ \\
\hline \multirow[t]{2}{*}{ Share $3+2$} & -0.183 & -0.158 & -0.107 & 0.060 & -0.008 \\
\hline & $(0.107)^{*}$ & $(0.057)^{* * *}$ & $(0.047)^{* *}$ & $(0.055)$ & $(0.036)$ \\
\hline \multirow[t]{2}{*}{ Graduate*Share $3+2$} & 0.078 & 0.063 & 0.059 & 0.138 & 0.031 \\
\hline & $(0.027)^{* * *}$ & $(0.013)^{* * *}$ & $(0.011)^{* * *}$ & $(0.018)^{* * *}$ & $(0.010)^{* * *}$ \\
\hline Observations & 133819 & 381189 & 381189 & 250463 & 381189 \\
\hline R-squared & 0.15 & 0.11 & 0.44 & 0.43 & \\
\hline
\end{tabular}

Notes: Dependent variable is a dummy indicating whether the individual is employed or not. In column (1) we use a sample of non-graduates aged 20-24 and of graduates aged 25-29, full time students excluded. All specifications control for region, age 30-34, sector and year dummies. In column (2) and (3) we add region*year dummies and sector*year dummies. In column (4) we use the sample in year 2004 and later. Estimation is by linear probability model in columns 1-4 and probit (marginal effects reported) in column 5. Clustered standard errors for linear probability model are reported in parentheses. ${ }^{*}$ significant at $10 \%$; ${ }^{* *}$ significant at $5 \%$; $* * *$ significant at $1 \%$. 
Table 5: The effect of $3+2$ reform on old and new $3+2$ graduates after 2004

\begin{tabular}{lcccc}
\hline & \multicolumn{2}{c}{ Males } & \multicolumn{2}{c}{ Females } \\
\hline \multirow{4}{*}{ Graduate 3+2 } & OLS & IV & OLS & IV \\
\cline { 2 - 5 } Old Graduate & -0.197 & -0.188 & -0.046 & -0.031 \\
& $(0.054)^{* * *}$ & $(0.055)^{* * *}$ & $(0.041)$ & $(0.042)$ \\
Share 3+2 & -0.125 & -0.118 & -0.087 & -0.087 \\
& $(0.018)^{* * *}$ & $(0.018)^{* * *}$ & $(0.019)^{* * *}$ & $(0.018)^{* * *}$ \\
Old Graduate*Share 3+2 & 0.075 & 0.136 & 0.159 & 0.217 \\
& $(0.046)$ & $(0.052)^{* * *}$ & $(0.049)^{* * *}$ & $(0.064)^{* * *}$ \\
Graduate 3+2*Share 3+2 & 0.181 & 0.169 & 0.141 & 0.140 \\
& $(0.031)^{* * *}$ & $(0.031)^{* * *}$ & $(0.029)^{* * *}$ & $(0.029)^{* * *}$ \\
Observations & 0.255 & 0.239 & 0.081 & 0.056 \\
R-squared & $(0.074)^{* * *}$ & $(0.077)^{* * *}$ & $(0.057)$ & $(0.061)$ \\
& & & & \\
& 141197 & 141197 & 109266 & 109266
\end{tabular}

Notes: Dependent variable is a dummy indicating whether the individual is employed or not. We use the sample in year 204 and later. All specifications control for region, age 30-34 and year dummies, a dummy for the reform of apprenticeship, a dummy for the reform of fixed-term contract and the interaction of demand dummies with the dummies for old graduate and $3+2$ graduate. The dummy "Old graduate" indicates a graduate of the prereform system while the dummy "Graduate $3+2$ " indicates a graduate of the new post-reform system (available from 2004 in LFS data). Only terms interacted with the regional share of $3+2$ graduates are shown. Estimation is by linear probability model and IV. Clustered standard errors are reported in parentheses. ${ }^{*}$ significant at $10 \%$; ** significant at $5 \%, * * *$ significant at $1 \%$. 
Table 6: The effect of $3+2$ reform on temporary employment probabilities: males and females

\begin{tabular}{|c|c|c|c|c|}
\hline & \multicolumn{2}{|c|}{ Males } & \multicolumn{2}{|c|}{ Females } \\
\hline & IV & IV interactions & IV & IV interactions \\
\hline \multirow[t]{2}{*}{ Graduate (dummy) } & 0.080 & 0.085 & 0.118 & 0.106 \\
\hline & $(0.008)^{* * *}$ & $(0.017)^{* * *}$ & $(0.007)^{* * *}$ & $(0.014)^{* * *}$ \\
\hline \multirow[t]{2}{*}{ Share $3+2$} & -0.036 & 0.005 & -0.085 & -0.030 \\
\hline & $(0.038)$ & $(0.042)$ & $(0.051)^{*}$ & $(0.058)$ \\
\hline \multirow[t]{2}{*}{ Graduate*Share $3+2$} & 0.074 & 0.038 & 0.008 & 0.016 \\
\hline & $(0.022)^{* * *}$ & $(0.055)$ & $(0.018)$ & $(0.033)$ \\
\hline \multirow[t]{2}{*}{ Reform_appr } & -0.003 & -0.008 & -0.009 & -0.016 \\
\hline & $(0.005)$ & $(0.014)$ & $(0.008)$ & $(0.020)$ \\
\hline \multirow[t]{2}{*}{ Graduate*Reform_appr } & -0.006 & 0.003 & 0.013 & 0.057 \\
\hline & $(0.016)$ & $(0.036)$ & $(0.015)$ & $(0.030)^{*}$ \\
\hline \multirow[t]{2}{*}{ Reform_fixedterm } & -0.002 & -0.018 & 0.002 & 0.001 \\
\hline & $(0.005)$ & $(0.011)$ & $(0.007)$ & $(0.013)$ \\
\hline \multirow[t]{2}{*}{ Graduate*Reform_fterm } & 0.002 & 0.116 & -0.026 & -0.020 \\
\hline & $(0.021)$ & $(0.058)^{* *}$ & $(0.021)$ & $(0.054)$ \\
\hline \multirow{2}{*}{ Graduate*Share $3+2 *$ North } & & -0.003 & & -0.039 \\
\hline & & $(0.061)$ & & $(0.042)$ \\
\hline \multirow[t]{2}{*}{ Graduate*Share $3+2 *$ South } & & 0.134 & & 0.073 \\
\hline & & $(0.072)^{*}$ & & $(0.062)$ \\
\hline \multirow[t]{2}{*}{ Graduate*Ref_appr*North } & & 0.006 & & -0.044 \\
\hline & & $(0.041)$ & & $(0.034)$ \\
\hline \multirow[t]{2}{*}{ Graduate*Ref_appr*South } & & -0.056 & & -0.096 \\
\hline & & $(0.054)$ & & $(0.047)^{* *}$ \\
\hline \multirow[t]{2}{*}{ Graduate*Ref_fterm*North } & & -0.092 & & -0.005 \\
\hline & & $(0.062)$ & & $(0.059)$ \\
\hline \multirow[t]{2}{*}{ Graduate*Ref_fterm*South } & & -0.227 & & -0.020 \\
\hline & & $(0.067)^{* * *}$ & & $(0.073)$ \\
\hline \multirow[t]{2}{*}{ Share $3+2$ Test $F$} & 33.82 & 39.99 & 28.84 & 36.72 \\
\hline & $(0.000)$ & $(0.000)$ & $(0.000)$ & $(0.000)$ \\
\hline \multirow[t]{2}{*}{ Graduate*Share $3+2$ Test $\mathrm{F}$} & 256.61 & 203.93 & 238.19 & 210.85 \\
\hline & $(0.000)$ & $(0.000)$ & $(0.000)$ & $(0.000)$ \\
\hline \multirow[t]{2}{*}{ Test of over-identifying } & 9.002 & 12.417 & 6.795 & 6.101 \\
\hline & $(0.061)$ & $(0.133)$ & 0.147 & $(0.635)$ \\
\hline Observations & 141663 & 141663 & 113138 & 113138 \\
\hline
\end{tabular}

Notes: Dependent variable is a dummy indicating whether the individual is employed under a temporary contract or not. All specifications controls for region, sector, age 30-34 and year dummies. In column 2 and 4 only the triple interaction terms interacted with "graduate dummy" are shown. Clustered standard errors are reported in parentheses. $*$ significant at $10 \% ; * *$ significant at $5 \% ; * * *$ significant at $1 \%$. 
Table 7: Robusteness check on temporary employment probabilities

\begin{tabular}{|c|c|c|c|c|c|}
\hline & (1) & $(2)$ & $(3)$ & (4) & $(5)$ \\
\hline & 2024 vs. 2529 & exp.proxy & trendreg\&sec & post 2004 & Probit \\
\hline & & & MALES & & \\
\hline \multirow[t]{2}{*}{ Graduate } & 0.006 & 0.189 & 0.083 & 0.129 & 0.088 \\
\hline & $(0.015)$ & $(0.013)^{* * *}$ & $(0.008)^{* * *}$ & $(0.022)^{* * *}$ & $(0.009)^{* * *}$ \\
\hline \multirow[t]{2}{*}{ Share $3+2$} & 0.004 & -0.037 & 0.033 & 0.011 & -0.005 \\
\hline & $(0.076)$ & $(0.037)$ & $(0.039)$ & $(0.046)$ & $(0.027)$ \\
\hline \multirow[t]{2}{*}{ Graduate*Share $3+2$} & -0.065 & 0.081 & 0.065 & -0.017 & 0.028 \\
\hline & $(0.041)$ & $(0.021)^{* * *}$ & $(0.022)^{* * *}$ & $(0.043)$ & $(0.015)^{*}$ \\
\hline \multirow[t]{2}{*}{ Observations } & 47073 & 141663 & 141663 & 94820 & 141663 \\
\hline & & & FEMALES & & \\
\hline \multirow[t]{2}{*}{ Graduate } & 0.033 & 0.260 & 0.119 & 0.150 & 0.126 \\
\hline & $(0.012)^{* * *}$ & $(0.011)^{* * *}$ & $(0.008)^{* * *}$ & $(0.021)^{* * *}$ & $(0.009)^{* * *}$ \\
\hline \multirow[t]{2}{*}{ Share $3+2$} & 0.188 & -0.090 & 0.010 & 0.027 & -0.065 \\
\hline & $(0.091)^{* *}$ & $(0.051)^{*}$ & $(0.056)$ & $(0.066)$ & $(0.032)^{* *}$ \\
\hline \multirow[t]{2}{*}{ Graduate*Share $3+2$} & -0.064 & 0.038 & 0.005 & -0.054 & -0.017 \\
\hline & $(0.034)^{*}$ & $(0.019)^{* *}$ & $(0.019)$ & $(0.036)$ & $(0.016)$ \\
\hline \multirow[t]{2}{*}{ Observations } & 37570 & 113138 & 113138 & 76650 & 113138 \\
\hline & \multicolumn{5}{|c|}{ ALL SAMPLE } \\
\hline \multirow[t]{2}{*}{ Graduate } & 0.028 & 0.240 & 0.110 & 0.152 & 0.112 \\
\hline & $(0.010)^{* * *}$ & $(0.009)^{* * *}$ & $(0.006)^{* * *}$ & $(0.017)^{* * *}$ & $(0.007)^{* * *}$ \\
\hline \multirow[t]{2}{*}{ Share $3+2$} & 0.084 & -0.053 & 0.029 & 0.023 & -0.025 \\
\hline & $(0.075)$ & $(0.040)$ & $(0.042)$ & $(0.050)$ & $(0.027)$ \\
\hline \multirow[t]{2}{*}{ Graduate*Share $3+2$} & -0.074 & 0.058 & 0.030 & -0.047 & 0.004 \\
\hline & $(0.027)^{* *}$ & $(0.016)^{* * *}$ & $(0.016)^{*}$ & $(0.030)$ & $(0.012)$ \\
\hline Observations & 84643 & 254801 & 254801 & 171470 & 254801 \\
\hline
\end{tabular}

Notes: Dependent variable is a dummy indicating whether the individual is employed with a temporary contracts or not. All specifications control for region, sector and year dummies. Estimation is by IV model (instruments are share $3+2$ degress in $\mathrm{t}-3$ and share of students enrolled in $3+2$ degrees in $\mathrm{t}-3$ ) and probit. Clustered standard errors for IV model are reported in parentheses. . Column 1 reports the estimates for an IV model comparing graduates in age range 25-29 with non graduates in age range 20-24. Column 2 reports the estimates for an IV model on base specification with the inclusion of a proxy for experience Column 3 reports the base IV results with the inclusion of region*year and sector*year trends. Column 4 replicates the model in column 3 for the period 2004-2007 and finally in column 6 we report a probit specification of our base model. * significant at $10 \%$; $* *$ significant at $5 \%$; ** significant at $1 \%$. 
Table 8: College wage premium in 2004 and in 2007: males

\begin{tabular}{|c|c|c|c|c|}
\hline \multirow{3}{*}{ Graduate } & OLS & OLS & OLS interaction & OLS old vs. new \\
\hline & 0.290 & 0.396 & 0.408 & \\
\hline & $(0.011)^{* * *}$ & $(0.061)^{* * *}$ & $(0.062)^{* * *}$ & \\
\hline \multirow[t]{2}{*}{ Year 2007} & 0.088 & 0.088 & 0.066 & 0.085 \\
\hline & $(0.007)^{* * *}$ & $(0.007)^{* * *}$ & $(0.014)^{* * *}$ & $(0.007)^{* * *}$ \\
\hline \multirow[t]{2}{*}{ Graduate*Year2007 } & -0.067 & -0.067 & -0.037 & \\
\hline & $(0.009)^{* * *}$ & $(0.009)^{* * *}$ & $(0.017)^{* *}$ & \\
\hline \multirow[t]{2}{*}{ Old Graduate } & & & & 0.349 \\
\hline & & & & $(0.055)^{* * *}$ \\
\hline \multirow[t]{2}{*}{ Old Graduate*Year 2007} & & & & -0.055 \\
\hline & & & & $(0.008)^{* * *}$ \\
\hline \multirow[t]{2}{*}{ Graduate $3+2$} & & & & 0.259 \\
\hline & & & & $(0.055)^{* * *}$ \\
\hline \multirow[t]{2}{*}{ Graduate*North } & & & 0.025 & \\
\hline & & & $(0.017)$ & \\
\hline \multirow[t]{2}{*}{ Graduate*South } & & & -0.038 & \\
\hline & & & $(0.019)^{* *}$ & \\
\hline \multirow[t]{2}{*}{ Year2007*North } & & & 0.042 & \\
\hline & & & $(0.017)^{* *}$ & \\
\hline \multirow[t]{2}{*}{ Year2007*South } & & & 0.000 & \\
\hline & & & $(0.019)$ & \\
\hline \multirow[t]{2}{*}{ Graduate*Year2007*North } & & & -0.059 & \\
\hline & & & $(0.021)^{* * *}$ & \\
\hline \multirow[t]{2}{*}{ Graduate*Year2007*South } & & & 0.004 & \\
\hline & & & $(0.024)$ & \\
\hline Faculty fixed-effects & No & Yes & Yes & Yes \\
\hline Observations & 24987 & 24936 & 24936 & 24936 \\
\hline R-squared & 0.30 & 0.30 & 0.30 & 0.29 \\
\hline
\end{tabular}

Notes: Dependent variable is the yearly wage both for high school students and graduates. All specifications controls for region, year and sector dummies, 5 dummies for final grades, age in brackets, years out of course, a dummy for temporary contract, degree subjects, regional unemployment rate in the age group 25-34. Estimation is by linear probability model. Final column replicates the same linear probability model distinguishing between old type and new type graduates (present only in 2007). Robust standard errors are reported in parenthesis. * significant at $10 \%$;** significant at $5 \%$; ${ }^{* *}$ significant at $1 \%$ 
Table 9: College wage premium in 2004 and in 2007: females

\begin{tabular}{|c|c|c|c|c|}
\hline \multirow{3}{*}{ Graduate } & OLS & OLS & OLS interaction & OLS old vs. new \\
\hline & 0.427 & 0.418 & 0.447 & \\
\hline & $(0.012)^{* * *}$ & $(0.086)^{* * *}$ & $(0.087)^{* * *}$ & \\
\hline \multirow[t]{2}{*}{ Year 2007} & 0.079 & 0.078 & 0.055 & 0.077 \\
\hline & $(0.008)^{* * *}$ & $(0.009)^{* * *}$ & $(0.017)^{* * *}$ & $(0.008)^{* * *}$ \\
\hline \multirow[t]{2}{*}{ Graduate*Year2007 } & -0.077 & -0.072 & -0.052 & \\
\hline & $(0.010)^{* * *}$ & $(0.010)^{* * *}$ & $(0.019)^{* * *}$ & \\
\hline \multirow[t]{2}{*}{ Old Graduate } & & & & 0.560 \\
\hline & & & & $(0.069)^{* * *}$ \\
\hline \multirow[t]{2}{*}{ Old Graduate*Year 2007} & & & & -0.062 \\
\hline & & & & $(0.009)^{* * *}$ \\
\hline \multirow[t]{2}{*}{ Graduate $3+2$} & & & & 0.459 \\
\hline & & & & $(0.069)^{* * *}$ \\
\hline \multirow[t]{2}{*}{ Graduate*North } & & & -0.044 & \\
\hline & & & $(0.018)^{* *}$ & \\
\hline \multirow[t]{2}{*}{ Graduate*South } & & & 0.052 & \\
\hline & & & $(0.024)^{* *}$ & \\
\hline \multirow[t]{2}{*}{ Year2007*North } & & & 0.021 & \\
\hline & & & $(0.020)$ & \\
\hline \multirow[t]{2}{*}{ Year2007*South } & & & 0.045 & \\
\hline & & & $(0.026)^{*}$ & \\
\hline \multirow[t]{2}{*}{ Graduate*Year $2007^{*}$ North } & & & -0.016 & \\
\hline & & & $(0.022)$ & \\
\hline \multirow[t]{2}{*}{ Graduate*Year2007*South } & & & -0.050 & \\
\hline & & & $(0.030)$ & \\
\hline Faculty fixed-effects & No & Yes & Yes & Yes \\
\hline Observations & 26187 & 26171 & 26171 & 26171 \\
\hline R-squared & 0.34 & 0.35 & 0.34 & 0.32 \\
\hline
\end{tabular}

Notes: Dependent variable is the yearly wage both for high school students and graduates. All specifications controls for region, year and sector dummies, 5 dummies for final grades, age in brackets, years out of course, a dummy for temporary contract, degree subjects, regional unemployment rate in the age group 25-34. Estimation is by linear probability model. Final column replicates the same linear probability model distinguishing between old type and new type graduates (present only in 2007). Robust standard errors are reported in parenthesis. * significant at $10 \%$;** significant at $5 \%$; ${ }^{* *}$ significant at $1 \%$

\section{APPENDIX TABLES}


Table 1: APPENDIX. LFS sample composition, individuals aged 25-34

\begin{tabular}{|c|c|c|}
\hline & Graduates & Non graduates \\
\hline North & 0.49 & 0.49 \\
\hline Centre & 0.18 & 0.16 \\
\hline South & 0.33 & 0.35 \\
\hline Employed & 0.86 & 0.89 \\
\hline Temporary contract & 0.28 & 0.13 \\
\hline Female & 0.58 & 0.41 \\
\hline Agriculture & 0.01 & 0.04 \\
\hline Mining & 0.01 & 0.01 \\
\hline Manufacture & 0.11 & 0.24 \\
\hline Construction & 0.02 & 0.09 \\
\hline Trade & 0.07 & 0.16 \\
\hline Hotel and restaurant & 0.01 & 0.05 \\
\hline Transports & 0.03 & 0.04 \\
\hline Finance & 0.06 & 0.02 \\
\hline Real estate & 0.21 & 0.07 \\
\hline Public sector & 0.06 & 0.04 \\
\hline Education and health & 0.23 & 0.07 \\
\hline Other public services & 0.04 & 0.06 \\
\hline No sector & 0.24 & 0.11 \\
\hline \multicolumn{3}{|c|}{ Number of (and percentage) } \\
\hline 1998 & $2273(10 \%)$ & 20156 \\
\hline 1999 & $2437(11 \%)$ & 19551 \\
\hline 2000 & $2513(11.7 \%)$ & 18880 \\
\hline 2001 & $2687(12.9 \%)$ & 18084 \\
\hline 2002 & $2829(13.6 \%)$ & 17884 \\
\hline 2003 & $2764(13.9 \%)$ & 17095 \\
\hline 2004 & $9587(14.1 \%)$ & 58009 \\
\hline 2005 & $9997(15.5 \%)$ & 54310 \\
\hline 2006 & $10073(16.9 \%)$ & 49495 \\
\hline 2007 & $10138(17.9 \%)$ & 46446 \\
\hline N. obs & 55298 & 319910 \\
\hline
\end{tabular}


Table 2: APPENDIX. CNVSU sample composition by year

\begin{tabular}{ccccccc}
\hline & graduates & $\begin{array}{c}\text { population aged 25-34 } \\
(2000-2007)\end{array}$ & $\begin{array}{c}\text { share of 3+2 } \\
\text { graduate }\end{array}$ & $\begin{array}{c}\text { share of } 3+2 \\
\text { degrees }\end{array}$ & $\begin{array}{c}\text { share of } 3+2 \\
\text { male enrolled }\end{array}$ & $\begin{array}{c}\text { share of } 3+2 \\
\text { female enrolled }\end{array}$ \\
\hline & & & & & & \\
1998 & 7613 & - & 0 & 0 & 0 & 0 \\
1999 & 8017 & - & 0 & 0 & 0 & 0 \\
2000 & 8499 & 479842 & 0 & 0.052 & 0.026 & 0.014 \\
2001 & 9042 & 475263 & 0.005 & 0.514 & 0.334 & 0.282 \\
2002 & 12163 & 471947 & 0.122 & 0.601 & 0.502 & 0.454 \\
2003 & 12354 & 471947 & 0.233 & 0.668 & 0.630 & 0.586 \\
2004 & 14146 & 451315 & 0.357 & 0.725 & 0.737 & 0.694 \\
2005 & 15856 & 447105 & 0.492 & 0.744 & 0.815 & 0.774 \\
2006 & 15809 & 438157 & 0.641 & 0.758 & 0.861 & 0.819 \\
2007 & 15796 & 430421 & 0.757 & 0.771 & 0.896 & 0.853
\end{tabular}

Notes: CNVSU data and LFS ISTAT 2000-2007 for population aged 25-34 in each region. 


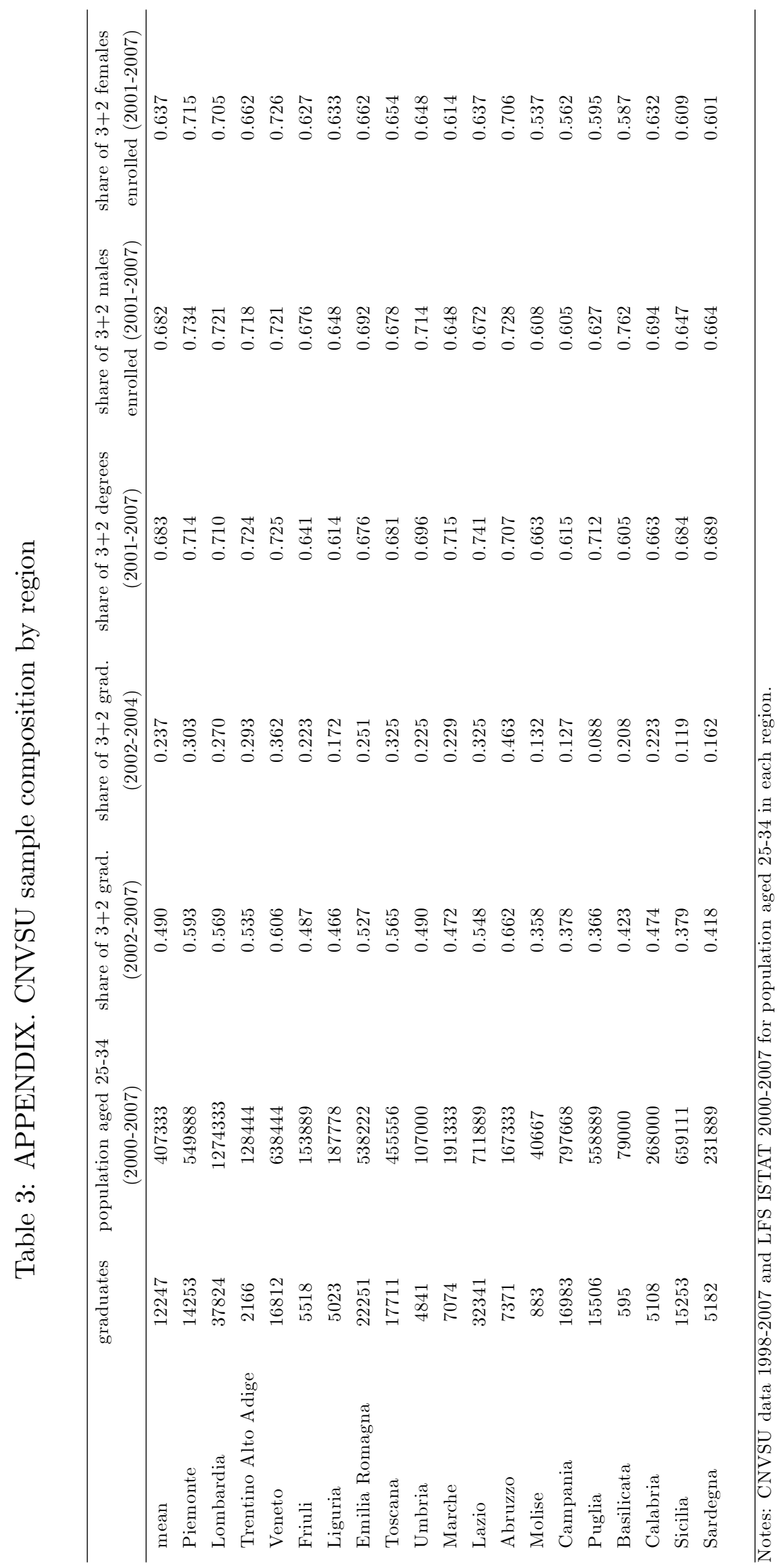


Table 4: APPENDIX. Descriptive statistics ISTAT 2004 and ISTAT 2007

\begin{tabular}{|c|c|c|c|}
\hline & 2004 & 2007 & 2004 and 2007 \\
\hline North & $0.50(0.50)$ & $0.55(0.49)$ & $0.53(0.49)$ \\
\hline Centre & $0.26(0.43)$ & $0.21(0.40)$ & $0.23(0.42)$ \\
\hline South & $0.24(0.41)$ & $0.24(0.41)$ & $0.24(0.41)$ \\
\hline Log wage & $6.91(0.40)$ & $6.99(0.37)$ & $6.94(0.38)$ \\
\hline Graduates & $0.63(0.48)$ & $0.71(0.45)$ & $0.66(0.47)$ \\
\hline \multicolumn{4}{|c|}{ Final grade in 4 intervals } \\
\hline Final grade 1 & $0.33(0.47)$ & $0.32(0.46)$ & $0.32(0.46)$ \\
\hline Final grade 2 & $0.25(0.43)$ & $0.24(0.42)$ & $0.25(0.43)$ \\
\hline Final grade 3 & $0.20(0.39)$ & $0.19(0.39)$ & $0.19(0.39)$ \\
\hline Final grade 4 & $0.22(0.41)$ & $0.25(0.42)$ & $0.23(0.42)$ \\
\hline \multicolumn{4}{|l|}{ Age in brackets } \\
\hline Less than 18 & $0.01(0.08)$ & $0.01(0.09)$ & $0.01(0.09)$ \\
\hline Age 19 & $0.26(0.43)$ & $0.21(0.39)$ & $0.23(0.40)$ \\
\hline Age $20-24$ & $0.21(0.41)$ & $0.35(0.46)$ & $0.30(0.44)$ \\
\hline Age 25-29 & $0.40(0.49)$ & $0.29(0.43)$ & $0.32(0.45)$ \\
\hline Age 30 and over & $0.12(0.31)$ & $0.14(0.32)$ & $0.14(0.32)$ \\
\hline Temporary contract & $0.38(0.48)$ & $0.38(0.49)$ & $0.38(0.48)$ \\
\hline Female & $0.50(0.49)$ & $0.52(0.49)$ & $0.51(0.49)$ \\
\hline Agriculture & $0.02(0.14)$ & $0.01(0.12)$ & $0.02(0.13)$ \\
\hline Industry & $0.24(0.42)$ & $0.20(0.40)$ & $0.21(0.41)$ \\
\hline Service & $0.74(0.43)$ & $0.79(0.41)$ & $0.77(0.42)$ \\
\hline
\end{tabular}

Notes: First column pools the ISTAT survey of high school graduates and the survey of college graduates interviewed in 2004 three years after diploma and graduation respectively. The second column pools the same surveys of high school and college graduates of 2004 interviewed in 2007 